\title{
Properties of plain concrete produced employing recycled aggregates and sea water
}

\author{
Highlights: \\ The use of Recycled Mixed Aggregates (RMA) leads to a reduction of landfills growth \\ The use of seawater represents another advance in sustainability by reducing fresh water consumption \\ Analysis of the possibility of using RMA and seawater in the production of concrete to be used in port \\ sites
}

The use of seawater in concretes with type III cement produced a denser cement matrix, which suffered low decrease by RMA addition.

\begin{abstract}
The generation of construction and demolition waste (C\&DW) is a noteworthy environmental and economic concern. The development of new applications in which Recycled Mixed Aggregates (RMA) can be used will lead to a reduction of landfills growth. Moreover, the use of seawater shall represent another advance in sustainability due to the consequent reduction of fresh water consumption, which can be a limited resource in certain areas. Although seawater is not generally recommended for concrete production, especially in reinforced concretes, seawater could be a viable replacement for fresh water in the production of plain concretes. This study intends to analyse the possibility of using RMA and seawater in the production of concrete to be used in port sites. This study is based on 3 different parameters: cement class, water source and RMA content. The results highlighted the beneficial effects of using type III cement, especially with regard to durability properties. The concretes produced employing RMA and type III cement achieved lower value of sorptivity coefficient and higher values of ultrasonic pulse velocity (UPV), chloride ion penetration resistance and electrical resistivity than those produced with natural aggregates and type I cement. Moreover the use of seawater in concretes with type III cement not only produced higher density and lower absorption capacity but also higher mechanical properties by creating a denser cement matrix, which proved to suffer low decrease by RMA addition.
\end{abstract}

Key words: mixed recycled aggregate, sea water, blast furnace cement, recycled concrete, properties

\section{INTRODUCTION}

Construction and demolition waste (C\&DW) generation is a major economic and environmental concern for European Union countries, as it represents the heaviest and most voluminous waste streams [1]. C\&DW still registers low recycling ratios, especially in Southern European countries. In these countries C\&DW is commonly comprised of several different materials such as concrete, old raw aggregates, ceramic bricks and gypsum. Following their treatment in a recycling plant the recycled aggregates sourced from this type of C\&DW are designated as recycled mixed aggregate (RMA) [2-4]. This mixed aggregate, while being comprised of a much greater percentage of ceramic material and other impurities has comparatively only a small percentage of concrete and raw aggregates. Currently most of RMA used in the construction industry are employed in low-strength required applications, such as road sub-base layers.

The use of RMA in concrete production has mainly been studied for non-structural elements $[5,6]$. Up to date, certain studies have analysed the possibility of using RMA for higher grade applications than those of non-structural concrete, such as medium-strength concrete [7] and 
high-performance concrete [7,8]. The consistency of the concretes produced with RMA may be affected by the high absorption capacity of the mixed recycled aggregates, which as known is much more than that of natural aggregates [5]. Therefore previous pre-wetting of the RMA is essential in order to maintain the similar fresh concrete properties found in those of conventional concrete (CC) [9]. An increase in the proportion of RMA leads to a decrease in the mechanical properties of the recycled concretes in their hardened state. In concretes of 25$50 \mathrm{MPa}$ compressive strength, strength dropped by up to $25 \%$ when $50 \%$ of natural coarse aggregates were replaced by RMA [3,5-7]. Furthermore the drop in the mechanical strength increases when the difference between the qualities of the new concrete and the old recycled aggregate increases $[5,10]$. Durability aspects are also negatively affected by more than $25 \%$ replacement of recycled aggregates. Higher replacement ratios were proved to significantly decrease the durability properties to the extent of creating limitations on the exposure possibilities of concrete [7].

Despite the fact that many international standards do not permit the use of seawater in concrete manufacturing, the influence of seawater as mixing water was studied. The reason why seawater should not be used in mixtures for reinforced concretes is the higher corrosion risk. However seawater can be suitable for use in plain un-reinforced concrete production. Several studies agree that in comparison with concretes mixed with fresh water, concrete mixed with seawater increases early-age strength and reduces setting time [11-14]. The chloride-ion content produces an acceleration of the cement setting and hardening. According to Shi et al. [15] at a given age, the hydration acceleration by $\mathrm{CaCl}_{2}$ caused a higher level of cement hydrate content in seawater mixed concretes. However, long-term studies revealed contradictory conclusions concerning the influence of seawater on cement hydrate content.

It is known that the concrete may suffer chemical attack due to the action of the high quantities of dissolved chloride, sulphate, sodium and magnesium contained in seawater [16]. Nevertheless according to various investigations $[11,14]$, the concrete produced with seawater using Blastfurnace Slag (BFS) cement and a low water-cement ratio results in low permeability, thus obtaining a high resistance to chloride penetration and corrosion of reinforcing steel. Moreover the chloride binding capacity is higher in BFS cements than that observed in Ordinary Portland Cement (OPC) due to its higher alumina content which effectively results in the production of Friedel's salt [17,18]. Nishida et al. [11] also found that the influence of the cement type was much greater when compared to that of mixing water in chloride diffusion.

Though, the main, underlying purpose of this study is to analyse the possibility of using recycled aggregate combined with seawater in the manufacturing of plain concrete and the consequence that would have on hardened concrete properties in comparison to those of conventional concretes (made using Portland cement, natural aggregates and fresh water). It was also decided that an analysis of this concrete's suitability for use in the construction of concrete elements such as dyke blocks on port sites (where seawater is easily accessible) should also be carried out. In order to comply with the Port of Barcelona's technical specifications for dyke blocks the concrete would need to have a minimum strength of $30 \mathrm{~N} / \mathrm{mm}^{2}$ and a minimum density of $2,300 \mathrm{~kg} / \mathrm{m}^{3}$.

Two experimental phases were carried out. In the first experimental phase (Phase 1) the concretes were produced using CEM I 42.5 SR (sulphate resistant Portland cement), natural aggregates coarser than $10 \mathrm{~mm}$ were substituted in volume for recycled coarse aggregates in 4 different ratios $(0 \%, 25 \%, 50 \%$ and $100 \%)$. The four concretes were produced using fresh water and sea water. In experimental phase 2, the four concretes were produced using CEM III / B 42.5 L / SR, Type III cement, BFS cement, with four different percentages of recycled aggregates (the volume of $0 \%, 25 \%, 50 \%$ and $100 \%$ of natural aggregates coarser than $10 \mathrm{~mm}$ 
were replaced by recycled aggregates) using only seawater. The recycled aggregates were sourced from a local C\&DW treatment plant. The hardened concrete tests were carried out in order to analyse the influence of the recycled mixed aggregates, seawater and cement type on the physical, mechanical and durability properties of the concrete.

\section{EXPERIMENTAL PHASE}

\subsection{Materials}

\subsubsection{Water}

This study was carried out employing two types of water: fresh mains water sourced directly from Barcelona's supply network, and seawater extracted directly from the Port of Barcelona. Table 1 shows the chemical properties of both waters.

\subsubsection{Cement}

Two cement classes were used, Type I Portland cement, CEM I 42.5 SR and Type III, BFS, cement CEM III/B 42.5 L/SR, whose chemical compositions are given in Table 2. Both types of cement were selected according to the recommendations laid down by international standards and the appropriate behaviour in seawater environments as described by several authors $[11,14,16]$.

\subsubsection{Aggregates}

Two types of aggregates were used: natural aggregate consisting of crushed limestone aggregates divided into three size fractions (sand $0-4 \mathrm{~mm}$, gravel $4-10 \mathrm{~mm}$ and gravel 10 20mm) and RMA aggregate sourced from Gestora de Runes de la Construcció SA, a local C\&DW treatment plant situated in Franqueses del Vallès (Barcelona).

The coarse RMA components were classified according to UNE-EN 933-11:2009 standard and the soluble sulphates content was determined according to UNE-EN 1744-1:2010 standard. The composition of the recycled mixed aggregates were defined: concrete $57.3 \%$; bricks and tiles $22.61 \%$; natural aggregates $12.55 \%$; asphalt $5.26 \%$; gypsum $1.76 \%$; plastic and glass $0.5 \%$. The percentage of impurities such as asphalts, gypsum, plastic and glass, was relatively low, representing only $7.5 \%$ of the total amount. However, the non-predominance of any concrete or ceramic aggregates does not permit it to be classified in any of the categories accepted by the majority of international standards, consequently the recycled aggregates employed were classified as RMA [2-4]. Although the percentage of gypsum was rather insignificant compared to that of the total materials forming the aggregate, the soluble sulphates content was quite high of $1.47 \%[3,19]$, and this could have an influence with respect to the concrete's durability. Nevertheless, according to previous research work carried out by authors [20] concretes produced using Sulphate resistant Portland cement, Type I, and BFS cement Type III combined with this type of mixed recycled aggregates was not affected by loss of durability.

The Particle size distributions of both types of aggregates were determined according to UNEEN 933-1:2012, and their grading distribution (see Figure 1) was found to be acceptable for concrete production. The RMA aggregates described had a grading fraction of 8-16 mm which was defined as having a lower nominal diameter than that of the natural aggregates (20mm). However, according to tests carried out in previous work [20], the recycled mixed aggregates' $20 \mathrm{~mm}$ of nominal size, as well as their flat shape (ceramic materials) influenced 
on greatly reducing the mechanical properties of the concretes. Therefore the use of a slightly lower nominal size can also be considered as recommendable for employing that type of aggregate in concrete production.

The physical and mechanical properties of each aggregate were characterized. The density and water absorption were determined according to UNE-EN 1097-6:2001, tests on the abrasion resistance and flakiness index were carried out following UNE-EN 1097-2:2010 and UNE-EN 933-3:2012, respectively. The RMA presented lower density and higher water absorption capacity than those of natural aggregates. The flakiness index and abrasion resistance (defined by Los Angeles index) of the RMA were also higher than those of the natural aggregates, the reason for this being the ceramic and old mortar attached to the concrete particles (see Table 3). The RMA characterization did not differ from those found by other authors when using RMA with similar compositions [3].

\subsubsection{Admixture}

The admixture used in concrete production was Glenium Sky 549. This admixture is a superplastizicer water-reducer, which has a density of $1,056 \mathrm{gr} / \mathrm{cm}^{3}$, based on polycarboxylates.

\subsection{Concrete production}

Concrete production was divided into two phases. In phase 1, all concretes were produced using Portland Cement CEM I 42.5 SR. Two series, Series 1 and Series 2, of concrete production were carried out using freshwater and sea water, respectively. In phase 2, a series (Series 3) of concrete production was carried out using BFS cement CEM III/B 42.5L /SR and sea water. In each series, four recycled mixed aggregates ratios $(0 \%, 25 \%, 50 \%$ and 100\%) were used to substitute the natural aggregates $(>10 \mathrm{~mm})$.

The mix proportion of the concrete produced with $0 \%$ of recycled aggregates (CC concrete) was created employing $300 \mathrm{~kg}$ of cement and a total water-cement ratio of 0.50 . The total volume of aggregates was formed using $50 \%$ of fine aggregates, with a fraction of $0-4 \mathrm{~mm}$, and $50 \%$ of coarse aggregates. The volume of coarse aggregates ( $50 \%$ of the total aggregates' volume) was formed mixing $30 \%$ of the $4-10$ fraction and the $70 \%$ of the $10-20 \mathrm{~mm}$ fraction aggregates. The recycled aggregate concretes, RC25, RC50 and RC100 were produced replacing volume of $25 \%, 50 \%$ and $100 \%$, respectively, of the natural aggregates (fraction 10$20 \mathrm{~mm}$ ) for recycled aggregates. Figure 2 shows the grading distribution of the four concretes produced. The concretes produced employing a higher percentages of recycled aggregates achieved a finer total grading distribution as a result of the finer fraction within the RMA (see Figure 1).

As mentioned above, the total water-cement (w/c) ratio was set at 0.5 for the $\mathrm{CC}$ concrete. The effective water-cement ratio of the $\mathrm{CC}$ concrete was determined (being the ratio between the effective water weight, which would react with cement, and the cement weight used for the concrete production) and fixed at a constant value for all concretes with 0.45 . Neville [16] defined the effective water in the concrete mix as the amount of water which occupies the space outside the aggregate particles. It was considered that the fine and coarse aggregates, which were used in dry condition, absorbed $80 \%$ and $20 \%$ water respectively, at concrete production. Those values were the water absorption capacity of aggregates submerged in water up to $30 \mathrm{~min}$ [8]. The moisture conditions of the recycled aggregates were intensively controlled in all the concretes produced in order to obtain the same effective water ratio. The 
RMA was used with approximately $80 \%$ humidity, in order to avoid bleeding or water surface layers influencing the mechanical properties of the concrete [9], and their effective absorption capacity was registered as $70 \%$. The total water amount of the concrete was considered as the amount of effective water weight plus the moisture (or absorbed water) of the aggregates (see Table 4).

Table 5 shows the mix proportioning used as well as the admixture amount used to achieve fluid consistencies, between $100-150 \mathrm{~mm}$ in the concrete slump test (S3 class following the EN 206-1:2000 standard).

The mechanical properties (compressive and splitting tensile strength and modulus of elasticity) and the resistance to chloride ion penetration were tested via the use of 15 cylindrical $(100 \varnothing \times 200 \mathrm{~mm})$ concrete specimens for each concrete mixture. The density, water absorption, porosity, capillary water absorption and electrical resistivity were tested via the use of $100 \mathrm{~mm}$ cubic specimens. The UNE EN 12390-2:2001 standard was followed for the production and curing of the concrete specimens. Concrete specimens were manually compacted using a metal rod and the specimens were covered with a plastic sheet and kept at air-curing for the first 24 hours. After 24 hours of casting, the specimens were de-moulded and then stored in a humidity room, at $21^{\circ} \mathrm{C}$ and $95 \%$ humidity, until the test ages were reached.

\subsection{Tests on hardened concrete}

\subsubsection{Physical properties}

Density, water absorption and permeable porosity test

The density, absorption and permeable porosity were measured at 28 days following the ASTM C 642-97 "Standard Test Method for Density, Absorption and Voids in Hardened Concrete'. Three cubic specimens were used in this test for each concrete mixture produced.

\subsubsection{Mechanical properties \\ Compressive and splitting tensile strengths and modulus of elasticity}

In each case the compressive strength, splitting tensile strength and modulus of elasticity were tested for each concrete mixture via the use of three $100 \emptyset$ x $200 \mathrm{~mm}$ cylindrical specimens. The mechanical properties of the concrete studied were determined using a compression machine with a loading capacity of $3000 \mathrm{kN}$. The compressive strength was measured at the ages of 7 and 28 days following UNE-EN 12390-3:2009 specifications. The splitting tensile strength and modulus of elasticity were tested after 28 days of casting following the UNE-EN 12390-6:2010 and UNE-EN 12390-13:2014 specifications, respectively.

\subsubsection{Durability properties Capillary water absorption}

The capillary water absorption, which was carried out in accordance with ISO 15148:2002(E), was assessed at 28 days after casting via the use of the $100 \mathrm{~mm}$ cubic concrete specimens. For sorptivity determination, the specimens were previously oven-dried at $40^{\circ} \mathrm{C}$ until constant weight. The bottom face of each of the specimens was immersed in water to a depth of a $5 \mathrm{~mm}$ (the lateral surfaces of the specimens were coated with impermeable resin). The cumulative water absorbed was recorded at different time intervals up to $120 \mathrm{~min}$ by weighing the specimens after removing the surface water using a dampened cloth. The sorptivity coefficient was calculated as the slope of the regression curve of the quantity of water absorbed by a unit surface area versus the square root of the elapsed time from the initial instant up to $120 \mathrm{~min}$. 
The data detailing the capillary water absorption are the results of the average obtained from three measurements taken.

\section{Chloride ion penetration test}

The test of chloride penetrability of concrete was conducted in accordance with ASTM C1202-12 specifications via the use of $100 \varnothing \times 50 \mathrm{~mm}$ concrete discs cut from the middle of two different $100 \varnothing \times 200 \mathrm{~mm}$ concrete cylinders. The resistance of the concrete to chloride ion penetration is represented by the total charge passed in Coulombs during a test period of 6 $\mathrm{h}$. In this study, the chloride ion penetrability test was carried out on concrete specimens at the ages of 28 days and each result was the average of two measurements.

\section{Electrical resistivity}

The electrical resistivity test was carried out after 28 days of casting via the use of $100 \mathrm{~mm}$ cubic specimens. Concrete resistance was measured in the laboratory with a basic electric device, the concrete specimens being in a saturated surface-dry condition. The measurements were carried out using an electric conductive gel spread on the contact surfaces, the copper plates being used as cathodes. Low-resistance contact between the concrete and the measurement circuit is critical in obtaining an accurate measurement. The strength applied on the cathodes can have significant effects on field resistance measurements, consequently the specimens were assessed employing a fixed weight at the same position upon the cathodes. The voltage and current across a sample of known dimensions were measured and the resistivity was determined. All specimens were tested at 28 days and each result was the average of 3 measurements taken.

\section{RESULTS AND DISCUSSION 3.1 Physical properties}

\section{Dry-density, water absorption and permeable porosity test}

The results obtained in the tests carried out on dry-density, water absorption and permeable porosity are shown in table 5 . The $100 \%$ substitution of natural aggregates $(>10 \mathrm{~mm})$ for recycled aggregates produced a decrease in concrete density of $9 \%$, while concretes with $50 \%$ and $25 \%$ showed dry-density drops of $4 \%$ and $2 \%$ respectively. Concrete density is highly dependent on the density of the recycled aggregates used, a fact which has been stated by several authors $[3,8]$. In our studies the reduction encountered was in accordance with the data given on reductions in other studies [6,8] (between 8-12\%) using RMA in high replacement ratios.

According to the results on concretes produced in Phase 1, the use of fresh or sea water did not have any negative influence on the physical properties of the four types of concretes. The concretes from series 3 showed slightly higher densities to those from phase 1 for a given RMA replacement ratio. Probably as a result of a denser cement paste.

The Technical Requirements Specification of the Port of Barcelona indicates that the concrete blocks must have a minimum density of $2.30 \mathrm{~kg} / \mathrm{dm}^{3}$. All the conventional concretes $(\mathrm{CC}-1$, CC-2 and CC-3) plus the 25\% recycled aggregate concretes of series 1, 2 and 3 (RC25-1, RC25-2 and RC25-3) met that requirement. In series 3 concrete a maximum of 50\% of RMA (RC50-3) could be allowed for dyke block production. The use of 50\% of RMA employing Portland cement for concrete production is possible when $50 \%$ of the aggregates are mixed together with 50\% steel slag aggregates [21]. 
Water absorption and permeable porosity followed similar tendencies to those of the density property, the increase in RMA replacement produced an increase in water absorption and porosity. The lowest values were found to be in concretes produced with cement type III, series 3, due to its pozzolanic reactions. It is widely accepted that the use of BFS cement as a partial replacement of ordinary Portland cement creates a denser matrix and reduces permeability and porosity $[22,23]$. Moreover Kou et al. found that the use of BFS cement contributed to performance improvement in concretes produced with recycled aggregate, this performance being lower in conventional concretes [24].

Figure 3 shows the relation between the amount of accessible pores in concretes produced with sea water in series 2 and 3 with respect to the amount of accessible pores in the corresponding concrete type produced with fresh water.

As mentioned previously, when type I cement was employed the concretes produced with sea or fresh water achieved similar accessible pores.

The concretes produced with type III cement and sea water achieved much lower permeable porous than concretes produced employing Portland cement. Moreover, the concretes produced employing BFS cement and recycled aggregates achieved a higher reduction of porosity than those produced with Portland cement (see Fig. 3). The mentioned difference in levels of porosity was probably a consequence of a pozzolanic reactivity and higher densification of cement paste caused by the fine material in the RMA [25]. Also Mohammed et al. [13] argued that the deposition of ettringite and Friedel's salt in concrete's air voids caused by diffused sulphates and chlorides also contributed to cement matrix densification.

The higher initial porosity of RMA produced higher reductions as a result of the seawater being absorbed by the aggregates, which may in turn contribute to the RMA pores being filled by new hydrates.

\subsection{Mechanical properties \\ 3.2.1 Compressive strength}

Table 6 shows that, in each series of concrete fabrication, the use of RMA not only decreases the mechanical properties of compressive and splitting tensile strength but also the modulus elasticity of concretes when compared to those of conventional concrete. According to the concretes produced in Phase 1, the concretes produced with sea water achieved similar compressive strength to that of the corresponding concrete produced with fresh water. Moreover, the influence of the sea water was similar in concretes produced with natural and recycled aggregates. RC100-1 and RC100-2 had 27.5\% and $28.5 \%$ of compressive strength reductions with respect to that of $\mathrm{CC}-1$ and $\mathrm{CC}-2$ respectively at 28 days. Mas et al. [5] and Martinez-Lage et al. [6] found similar compressive strength reductions when RMA was used to replace natural aggregates.

The compressive strength of $\mathrm{CC}, \mathrm{RC} 25, \mathrm{RC} 50$ and $\mathrm{RC} 100$ concretes produced at series 3 was $11 \%, 26 \%, 20 \%$ and $28 \%$ respectively, proving to be higher than that of those concretes produced at series 2. The influence of the recycled aggregates on the reduction of the compressive strength was lower in series 3 than that in series 1 and 2. RC100-3 achieved $17 \%$ lower compressive strength than that of CC-3, which proved to be lower than the concretes produced with Portland Type I cement. The increase of pozzolanic reactions within recycled aggregates has been noted in many studies $[24,26]$.

The concretes produced with recycled aggregates achieved a higher increase of compressive strength from 7 to 28 days of age. The concrete produced with 100\% of RMA showed an 
increase of between 20-42\% (in different series) and CC concretes achieved an increase of between 6- $25 \%$. This increase was in all probability due to the reaction of the binder components with fine material inherent in the RMA.

The Port of Barcelona's Technical Requirements Specifications stipulated a minimum of 30 MPa of compressive strength. All concretes satisfied that prescribed limit at 28 days of age (see Table 6).

Figure 4 shows the ratio of compressive strength of the recycled aggregate concrete with respect to that of conventional concrete in each series. The recycled concretes made in series 3 showed a lower decrease of compressive strength with respect to that of $\mathrm{CC}$ concrete when compared to recycled concretes produced in series 1 and series 2 .

\subsubsection{Splitting tensile strength}

As depicted in table 6, the splitting tensile strength of concretes decreased in accordance with the higher amount of recycled aggregates employed in concrete production. According to previous work carried out by authors [20], the $20 \mathrm{~mm}$ nominal size of RMA as well as their flat shape influenced in the obtaining of lower splitting tensile strength. However, it is also known that the concretes produced employing recycled concrete aggregates can improve the splitting tensile strength of concrete [26,27]. With respect to phase 1 , the concretes produced in series 2 (with sea water) achieved a slightly lower strength than those of the corresponding concretes in series 1 .

The concretes produced in series 3, which employed type III cement and sea water, achieved the highest strength. Although, the splitting tensile strength of concretes produced with RMA decreased, the concretes of series 3, even with a replacement of $100 \%$ of RMA, achieved higher values than those of CC concretes produced in any of series 1 or series 2 .

\subsubsection{Modulus of elasticity}

The RMA replacement produced modulus of elasticity reductions for given cement and water types throughout all the series produced (see Table 6). The reduction of modulus of elasticity is proportional to the modulus of elasticity of the aggregates [28], which in turn depends on its density, a fact exposed by Lydon and Balendran [29]. The use of RMA in concrete production results in a reduction of the concrete's modulus elasticity. The modulus of elasticity of concretes containing 100\% RMA was observed to decline in average values, ranging from $25 \%$ to $32 \%$. These reductions were in accordance with those results determined by MartinezLage et al. [6] and Gonzalez-Corominas and Etxeberria [8] in concretes produced with high replacement ratios of RMA. The results were similar to those of the other mechanical properties tested, in as far as the use of seawater did not influence the modulus of elasticity of concretes produced with type I cement.

It was determined that series 3 concretes, produced with type III cement and sea water achieved the highest modulus of elasticity. The reason for this being a higher development of the cement matrix hydration as was observed in the density and permeable pore test.

\subsection{Durability properties}

\subsubsection{Capillary water absorption}

The results of assessing the concrete specimens' capillary water absorption over a period of 120 min are shown in Figure 5. The capillary water absorption of concretes produced with 
RMA showed much higher values than those of conventional concretes, throughout all the concrete series, this was probably due to the connectivity of the porous in each grain of the coarse mixed aggregate, a fact which has also been reported by other researchers $[30,31]$.

According to the results achieved by concretes produced in Phase 1 (with Portland Cement), the use of sea water reduced the capillary absorption capacity of concretes produced with high percentages of recycled aggregates, probably due to the presence of more mineral salts within the chemical composition of that water and consequently in the pores of aggregates and cement paste. The capillary absorption capacity of concretes produced with Portland cement was higher than those produced with Type III BFS Cement. The pozzolanic activity of slag reduces capillary water absorption as a result of the increase of density of cement porous structure due to the formation of the secondary CSH gel, which fills capillary pores [32]. The correlation coefficients of each of the concretes curves values were determined. The concretes produced with cement Portland obtained a value between 0.95 and 0.97 . The correlation coefficient of the concretes produced employing type III BFS cement was between 0.92 and 0.95. There was not difference between $\mathrm{CC}$ and RC concretes.

The sorptivity results (see Table 6) showed that the series 3 concretes produced employing $100 \%$ of RMA had a lower sorptivity coefficient when compared to those from the natural aggregate concrete produced with type I cement. The present sorptivity findings are consistent with the observations reported by other authors [33]. According to Neville [16], concretes produced with the water/cement ratio of 0.4 and 0.6 achieve sorptivity values of 0.09 $\mathrm{mm} / \mathrm{min}^{0.5}$ and $0.17 \mathrm{~mm} / \mathrm{min}^{0.5}$, respectively.

\subsubsection{Chloride ion penetration}

Table 6 shows the amount of electric flux through the concrete specimens at 28 days of age, indicating the resistance to chloride ion penetration of the specimens.

According to the results obtained from the concretes produced in Phase 1, the use of RMA decreased the resistance to chloride ion penetration, a fact which has also been detected in other works [20]. Only the conventional concretes of series 1 and 2 were classified as possessing moderate chloride penetrability. It was also determined that the use of sea water in series 2 concrete production considerably reduced the resistance of chloride ion penetration in concrete produced with $100 \%$ of recycled aggregates.

All concrete mixed with type III cement displayed a total charge passed value of between 800 and 1400 coulombs, which is defined according to the classifications of the testing method as corresponding to a very low or low to ion chloride penetrability. According to these results, the electric flux decreased when the concretes were mixed employing type III cement, indicating that BFS content improved the chloride resistance of concrete by improving its impermeability and chloride binding capacity, which has been previously reported in other studies $[23,34,35]$. The beneficial influence of BFS in chloride resistance of concretes was clearly observed, nevertheless the reduction of chloride ion penetration noted by Shi et al. [15] when combining metakaolin with seawater was not discovered when using BFS.

Although the use of RMA in concrete production had a negative influence on the resistance of chloride ion penetration. In series 3 concrete, the electric flux recorded in the concretes with $100 \%$ of RMA was $60 \%$ lower than that of the conventional concrete from series 2 and series 1 , which highlights the beneficial influence of BFS in cements where durability is concerned.

\subsubsection{Electrical resistivity}


Table 6 shows that the electrical resistivity of concretes (they were saturated with water) decreased when higher percentages of recycled aggregates were used for concrete production. Mixtures from series 1 and 2, produced with type I cement had a high and very high corrosion risk, respectively. The use of seawater reduced electric resistance between 41-61\% with respect to electric resistance of concretes with the same RMA replacement ratio.

It can be observed that concretes produced with type III cement showed significant higher resistance to electric flux. The porosity refinement, due to the pozzolanic hydration enhancement, increased the electrical resistance to between $78-88 \%$ of those concretes produced with type I cement for a given RMA replacement ratio and water type. Concretes made with $100 \%$ of RMA from series 3 showed a significantly higher value than those of conventional concretes from series 1 and 2. According to Langford and Broomfield [36], the mixes from series 3, produced with type III cement, showed low and moderate corrosion risk, respectively.

These results, as other researchers have already confirmed [11], endorse the fact that it is in reality the cement type that is the major influence on electrical resistivity, playing an active part above that of the replacement ratio of RMA or the water type used.

\section{CONCLUSIONS}

The following conclusions can be drawn from the results of this study:

- The results of a comparative study between conventional concrete and recycled aggregate concrete, which employed the same type of cement and water, concluded that the concrete produced employing recycled coarse mixed aggregates in substitution of natural aggregates resulted in a reduction of density, mechanical and durability properties.

- The reduction of density and mechanical properties of concretes produced employing up to $50 \%$ of RMA was lower than $5 \%$ and $15 \%$ respectively in comparison to those values of $\mathrm{CC}$ concretes. However, the absorption and durability properties values of concretes produced using up to $50 \%$ of MRA doubled the values obtained by the CC concretes.

- The porosity and permeability of RMA had an influence on the reduction of the values of those properties. However, comparative tests of the permeable porous between RMA concretes produced with fresh water and those of sea water showed that the use of sea water in the production of the RMA concretes improved the obtained values in durability.

- The concretes produced with BFS cement and sea water achieved the highest values of mechanical and durability properties. The influence of RMA was lower than those found in concretes produced with Portland cement.

- The concretes produced employing up to $100 \%$ of recycled coarse aggregates using type III blast furnace slag cement and sea water, achieved more adequate durability properties than those of conventional concrete produced employing Portland cement, freshwater and raw aggregates.

For the production of plain concrete elements such as dyke blocks in port areas (minimum of $2.3 \mathrm{~kg} / \mathrm{dm} 3$ of density and $30 \mathrm{MPa}$ of compressive strength are required) a $25 \%$ maximum of recycled aggregates should be employed when Portland cement is being used with fresh or sea water. However, a suitable concrete could be produced using $50 \%$ of recycled aggregate when 
Type III Blast furnace slag cement and sea water are employed together. The density of the concrete being the limiting property.

In general it can be assumed that the use of recycled aggregates as well as the type of cements used for concrete production have a greater influence on the properties of plain concretes than the use of sea water. Concretes produced employing BFS cement achieved excellent properties even when they were produced using recycled aggregates and sea water. However, more experimental work needs to be carried out in order to guarantee the adequate properties and the durability of concretes.

\section{Acknowledgements}

The authors wish to acknowledge the financial support of The Ministry of Economy and Competitiveness of the Government of Spain (MINECO) for providing funds for the INNPACT project (IPT-2012-1093-310000) and also the European Regional Development Fund (FEDER).

\section{References}

[1] Eurostat. Waste statistics in Europe. URL: http://epp.eurostat.ec.europa.eu/, (n.d.).

[2] S.C. Angulo, P.M. Carrijo, A.D. Figueiredo, A.P. Chaves, V.M. John, On the classification of mixed construction and demolition waste aggregate by porosity and its impact on the mechanical performance of concrete, Mater. Struct. 43 (2010) 519-28.

[3] F. Agrela, M. Sánchez de Juan, J. Ayuso, V.L. Geraldes, J.R. Jiménez, Limiting properties in the characterisation of mixed recycled aggregates for use in the manufacture of concrete, Constr. Build. Mater. 25 (2011) 3950-3955. doi:10.1016/j.conbuildmat.2011.04.027.

[4] R.V. Silva, J. de Brito, R.K. Dhir, Properties and composition of recycled aggregates from construction and demolition waste suitable for concrete production, Constr. Build. Mater. 65 (2014) 201-217. doi:10.1016/j.conbuildmat.2014.04.117.

[5] B. Mas, A. Cladera, T. del Olmo, F. Pitarch, Influence of the amount of mixed recycled aggregates on the properties of concrete for non-structural use, Constr. Build. Mater. 27 (2012) 612-622. doi:10.1016/j.conbuildmat.2011.06.073.

[6] I. Martínez-Lage, F. Martínez-Abella, C. Vázquez-Herrero, J.L. Pérez-Ordóñez., Properties of plain concrete made with mixed recycled coarse aggregate, Constr. Build. Mater. 37 (2012) 171-176. doi:10.1016/j.conbuildmat.2012.07.045.

[7] C. Hoffmann, S. Schubert, A. Leemann, M. Motavalli, Recycled concrete and mixed rubble as aggregates: Influence of variations in composition on the concrete properties and their use as structural material, Constr. Build. Mater. 35 (2012) 701-709. doi:10.1016/j.conbuildmat.2011.10.007.

[8] A. Gonzalez-Corominas, M. Etxeberria, Properties of high performance concrete made with recycled fine ceramic and coarse mixed aggregates, Constr. Build. Mater. 68 (2014) 618-626. doi:10.1016/j.conbuildmat.2014.07.016.

[9] C.S. Poon, Z.H. Shui, L. Lam, H. Fok, S.C. Kou, Influence of moisture states of natural and recycled aggregates on the slump and compressive strength of concrete, Cem. Concr. Res. 34 (2004) 31-36. doi:10.1016/S0008-8846(03)00186-8. 
[10] A. Gonzalez-Corominas, M. Etxeberria, Experimental analysis of properties of high performance recycled aggregate concrete, Constr. Build. Mater. 52 (2014) 227-235. doi:10.1016/j.conbuildmat.2013.11.054.

[11] Takahiro Nishida, Nobuaki Otsuki, Hiroki Ohara, Zoulkanel Moussa Garba-Say, Tomohiro Nagata, Some Considerations for Applicability of Seawater as Mixing Water in Concrete, J. Mater. Civ. Eng. 27(7) (2015)

[12] S.K. Kaushik, S. Islam, Suitability of sea water for mixing structural concrete exposed to a marine environment, Cem. Concr. Compos. 17 (1995) 177-185. doi:10.1016/09589465(95)00015-5.

[13] T.U. Mohammed, H. Hamada, T. Yamaji, Performance of seawater-mixed concrete in the tidal environment, Cem. Concr. Res. 34 (2004) 593-601. doi:10.1016/j.cemconres.2003.09.020.

[14] N. Otsuki, T. Saito, Y. Tadokoro, Possibility of Sea Water as Mixing Water in Concrete, Journal of Civil Engineering and Architecture 6 (2012) 1273-1279.

[15] Z. Shi, Z. Shui, Q. Li, H. Geng, Combined effect of metakaolin and sea water on performance and microstructures of concrete, Constr. Build. Mater. 74 (2015) 57-64. doi:10.1016/j.conbuildmat.2014.10.023.

[16] A.M. Neville, Properties of Concrete, 4th ed., 1995.

[17] M.V.A. Florea, H.J.H. Brouwers, Chloride binding related to hydration products, Cem. Concr. Res. 42 (2012) 282-290. doi:10.1016/j.cemconres.2011.09.016.

[18] M.V. a. Florea, H.J.H. Brouwers, Modelling of chloride binding related to hydration products in slag-blended cements, Constr. Build. Mater. 64 (2014) 421-430. doi:10.1016/j.conbuildmat.2014.04.038

[19] EHE. Instrucción del hormigón estructural (Spanish Concrete Structural Code), (2008).

[20] M. Etxeberria; A. Gonzalez, I. Valero, Application of low grade recycled aggregates for nonstructural concrete production in the city of Barcelona, Third International Conference on Sustainable Construction Materials and Technologies set for Kyoto, Japan, August 2013

[21] Miren Etxeberria, Jesus Manuel Fernandez, Jussara Limeira, Secondary aggregates and sea water employment for sustainable concrete dyke blocks production: case study, Construction and Building Materials 113 (2016) 586-595

[22] C.-M. Aldea, F. Young, K. Wang, S.P. Shah, Effects of curing conditions on properties of concrete using slag replacement, Cem. Concr. Res. 30 (2000) 465-472. doi:10.1016/S0008-8846(00)00200-3.

[23] H.-W. Song, V. Saraswathy, Studies on the corrosion resistance of reinforced steel in concrete with ground granulated blast-furnace slag--An overview., J. Hazard. Mater. 138 (2006) 226-33. doi:10.1016/j.jhazmat.2006.07.022.

[24] S.C. Kou, C.S. Poon, F. Agrela, Comparisons of natural and recycled aggregate concretes prepared with the addition of different mineral admixtures, Cem. Concr. Compos. 33 (2011) 788-795. doi:10.1016/j.cemconcomp.2011.05.009.

[25] M. Pepe, E.A.B. Koenders, C. Faella, E. Martinelli, Structural concrete made with recycled aggregates: Hydration process and compressive strength models, Mech. Res. Commun. 58 (2014) 139-145. doi:10.1016/j.mechrescom.2014.02.001. 
[26] A. Ajdukiewicz, A. Kliszczewicz, Influence of recycled aggregates on mechanical properties of HS/HPC, Cem. Concr. Compos. 24 (2002) 269-279. doi:10.1016/S09589465(01)00012-9.

[27] Muzaffer Mansur Tüfekçi · Özgür Çakır, An Investigation on Mechanical and Physical Properties of Recycled Coarse Aggregate (RCA) Concrete with GGBFS, Int J Civ Eng DOI 10.1007/s40999-017-0167-x

[28] H. Dilbas• Ö. Cakir M. Simsek, Recycled Aggregate Concretes (RACs) for Structural Use: An Evaluation on Elasticity Modulus and Energy Capacities, Int J Civ Eng (2017) 15:247-261, DOI 10.1007/s40999-016-0077-3

[29] F. Lydon, R.. Balendran, Some observations on elastic properties of plain concrete, Cem. Concr. Res. 16 (1986) 314-24.

[30] S.M. Levy, P. Helene, Durability of recycled aggregates concrete: a safe way to sustainable development, Cem. Concr. Res. 34 (2004) 1975-1980. doi:10.1016/j.cemconres.2004.02.009.

[31] E. Wirquin, R. Zaharieva, F. Buyle-Bodin, Use of water absorption by concrete as a criterion of the durability of concrete - application to recycled aggregate concrete, Mater. Struct. 33 (2000) 403-8.

[32] A. Hadjsadok, S. Kenai, L. Courard, F. Michel, J. Khatib, Durability of mortar and concretes containing slag with low hydraulic activity, Cem. Concr. Compos. 34 (2012) 671677. doi:10.1016/j.cemconcomp.2012.02.011.

[33] S.C. Kou, C.S. Poon, H. Wan, Properties of concrete prepared with low-grade recycled aggregates C \& D Waste, Constr. Build. Mater. 36 (2012) 881-889.

[34] H. Yiğiter, H. Yazıcı, S. Aydın, Effects of cement type, water/cement ratio and cement content on sea water resistance of concrete, Build. Environ. 42 (2007) 1770-1776. doi:10.1016/j.buildenv.2006.01.008.

[35] S.A. Bernal, R. Mejía de Gutiérrez, J.L. Provis, Engineering and durability properties of concretes based on alkali-activated granulated blast furnace slag/metakaolin blends, Constr. Build. Mater. 33 (2012) 99-108. doi:10.1016/j.conbuildmat.2012.01.017.

[36] J. Langford, P. Broomfiel, Monitoring the corrosion of reinforcing steel., Constr. Repair. 1 (1987) 32-6. 


\section{Properties of plain concrete produced employing recycled aggregates and sea water}

Miren Etxeberria Larrañaga*1, Andreu Gonzalez Corominas ${ }^{1}$

Miren Etxeberria Larrañaga (*corresponding author)

Associate professor, Dr. Eng.

Email: miren.etxeberria@upc.edu

Department of Civil and Environmental Engineering, Universitat Politecnica de

Catalunya.BarcelonaTECH, Jordi Girona, 1-3, Barcelona 08034, Spain. Telephone: +34

934011788

Andreu Gonzalez Corominas

Researcher, $\mathrm{PhD}$

Email: andreu.gonzalez-corominas@upc.edu

Department of Civil and Environmental Engineering, Universitat Politecnica de

Catalunya.BarcelonaTECH, Jordi Girona, 1-3, Barcelona 08034, Spain. Telephone: +34

934011788

Name of supporting funds Organization:

Ministerio de Economía y Competitividad

Award Number: IPT-2012-1093-310000 | Recipient: Miren Etxeberria, Dr. 


\section{ANSWER TO REVIEWERS}

All the changes are possible to see in the file "manuscript with correction", It has been uploaded as supplementary material.

\section{Editor Note:}

\section{COMMENT 1.}

- Your manuscript needs English editing by a native English professional editor. ANSWER

The manuscript has been corrected by a native English professional editor.

\section{COMMENT 2.}

-Make the lines in your figure much ticker to become more clear in the final version. I also suggest that the figures 3 and 4 to be presented by points and lines instead of presenting by columns.

ANSWER

The lines present on all figures have been modified.

The Figures 3 and 4 have been modified to be presented by points and lines.

\section{COMMENT3.}

-The number of your references can be reduced to 30-40. Keep the most relevant ones which have been published in the credible Journals and omit the rest. To update your references, you need to go to IJCE website and find 2-3 recent papers( 2017 with DOI) and relevant to you article and use them as your references in the text and list of references.

ANSWER

The number of previous referenced have been reduced. And two important references of papers published in the IJCE have been added.

[27] Muzaffer Mansur Tüfekçi · Özgür Çakır, An Investigation on Mechanical and Physical Properties of Recycled Coarse Aggregate (RCA) Concrete with GGBFS, Int J Civ Eng DOI 10.1007/s40999-017-0167-x

[28] H. Dilbas Ö. Cakir M. Simsek, Recycled Aggregate Concretes (RACs) for Structural Use: An Evaluation on Elasticity Modulus and Energy Capacities, Int J Civ Eng (2017) 15:247-261, DOI 10.1007/s40999-016-0077-3

\section{COMMENT4.}

-When you resubmit your revised version, include a reply letter, indicating each reviewer's comment and then your respond, point by point. You need also to indicate that in what part of your manuscript, such comment has been implemented. The final decision about your article is based on how well you implement the comments. 


\section{ANSWER}

Answers to all comments are given adequately.

\section{The references have been also corrected.}

\section{Reviewer \#2:}

\section{COMMENT 1.}

Conclusion section should be enriched and should be discussed in details. For example; relations between physical, mechanical and durability properties should be established and should be discussed in details. I recommend it to be published only after minor revisions.

ANSWER

The conclusions have been enriched and rewritten.

\section{COMMENT 2.}

* Page 5/Line 46: can be: Tests on hardened concrete

* Table 1 should be Table 2: Chemical composition of cements

* Table 5 can be : Densities, water absorption and porosity test results of concrete mixes

* Table 6 should be : Mechanical and durability test results of concrete mixes

* Figure 5 can be re-drawn by using trendiness and correlation coefficients can be calculated.

* Reference numbers $39,50,51,52$ are missing in reference list.

\section{ANSWER}

- Page 5/Line 46, The title has been changed to "Tests on hardened concrete"

- The numbering of the table has been corrected to Table 2.

- The title of Table 5 has been changed to "Densities, water absorption and porosity test results of concrete mixes"

- The title of Table 6 has been changed to "Mechanical and durability test results of concrete mixes"

- The authors found an error in the description of the section "2.3.3- Capillary water absorption". The cumulative water absorbed was recorded at different time intervals up to $120 \mathrm{~min}$. The previous values given in Figure 5 were wrongly described according the time of data acquisition and data values. The Figure 5 was modified, the Time values of $X$ axis were modified to $\left(\min ^{\wedge} 0.5\right)$ and the values were extended to $120 \mathrm{~min}$.

For each curve the trend lines was considered and the correlation coefficient of the value of each of the curve was determined. They are described in the text (section 3.3.1) of the manuscript.

- The re-numbering of the references has been carried out. 


\section{Reviewer \#3:}

COMMENT 1.

Grammatical Corrections needed.

ANSWER

The grammatical errors of the manuscript have been corrected

COMMENT 2.

References should be checked.

ANSWER

References have been checked and corrected

\section{COMMENT 3.}

Some of the abbreviation terms full form is not mentioned.

ANSWER

All the abbreviations have been corrected. 
LIST OF TABLES

Table 1. Chemical compositions of fresh water and seawater.

Table 2. Chemical composition of cements

Table 3. Physical properties of the aggregates.

Table 4. Concrete proportioning of each dosage

Table 5. Densities, water absorption and porosity test results of concrete mixes

Table 6. Mechanical and durability test results of concrete mixes 
Table 1. Chemical compositions of fresh water and seawater.

\begin{tabular}{|c|c|c|c|c|c|c|c|c|c|c|}
\hline Element & $\mathbf{C a}$ & $\mathbf{M g}$ & $\mathbf{N a}$ & $\mathbf{K}$ & $\mathbf{S}$ & $\mathbf{S r}$ & $\mathbf{B}$ & $\mathbf{C l}$ & $\mathbf{S O}_{4}$ & Br- \\
\hline Freshwater (\%) & 0.010 & 0.002 & 0.006 & 0.001 & 0.003 & 0.000 & 0.000 & 0.006 & 0.013 & 0.000 \\
\hline Seawater (\%) & 0.049 & 0.136 & 1.164 & 0.042 & 0.096 & 0.001 & 0.001 & 2.080 & 0.282 & 0.006 \\
\hline
\end{tabular}

Table 2. Chemical composition of cements

\begin{tabular}{|c|c|c|c|c|c|c|c|c|c|c|}
\hline Composition & $\mathrm{Fe}_{2} \mathrm{O}_{3}$ & $\mathrm{MnO}$ & $\mathrm{TiO}_{2}$ & $\mathbf{C a O}$ & $\mathrm{K}_{2} \mathrm{O}$ & $\mathrm{P}_{2} \mathrm{O}_{5}$ & $\mathrm{SiO}_{2}$ & $\mathrm{Al}_{2} \mathrm{O}_{3}$ & $\mathrm{MgO}$ & $\mathrm{Na}_{2} \mathrm{O}$ \\
\hline $\begin{array}{c}\text { CEM I 42.5 } \\
\text { SR (\%) }\end{array}$ & 4.58 & 0.02 & 0.20 & 63.88 & 0.78 & 0.10 & 20.71 & 4.22 & 1.68 & 0.17 \\
\hline $\begin{array}{c}\text { CEM III/B } \\
\mathbf{4 2 . 5} \mathbf{~ L / S R} \\
(\%)\end{array}$ & 1.56 & 0.25 & 0.72 & 49.76 & 0.88 & 0.09 & 28.42 & 8.07 & 6.02 & 0.69 \\
\hline
\end{tabular}

Table 3. Physical properties of the aggregates.

\begin{tabular}{|c|c|c|c|c|}
\hline \multirow[b]{2}{*}{ Physical properties } & \multicolumn{3}{|c|}{ Natural aggregates } & \multirow{2}{*}{$\begin{array}{c}\text { Recycled Mixed } \\
\text { Aggregates } \\
\text { 8-16mm }\end{array}$} \\
\hline & 0-4 mm & 4-10 $\mathrm{mm}$ & $10-20 \mathrm{~mm}$ & \\
\hline Density after drying $\left(\mathrm{kg} / \mathrm{dm}^{3}\right)$ & 2.59 & 2.62 & 2.63 & 2.02 \\
\hline Water Absorption (\%) & 2.35 & 0.86 & 0.67 & 11.35 \\
\hline LA coefficient $(\%)$ & - & 19.80 & 19.80 & 33.60 \\
\hline Amount of fines $(<0.063 \mathrm{~mm})(\%)$ & 5.69 & - & - & 6.03 \\
\hline Flakiness Index (\%) & - & 7.81 & 10.35 & 18.36 \\
\hline
\end{tabular}

Table 4. Concrete proportioning of each dosage. (1/2/3 were the series designation)

\begin{tabular}{|c|c|c|c|c|c|c|c|c|}
\hline \multirow{2}{*}{$\begin{array}{l}\text { Concrete } \\
\text { reference* }\end{array}$} & \multicolumn{3}{|c|}{ Natural aggregates(kg) } & \multirow{2}{*}{$\begin{array}{l}\text { RMA } \\
8-16 \text { mm }\end{array}$} & Cements & \multirow{2}{*}{$\begin{array}{l}\text { TOTAL } \\
\text { water }(\mathbf{k g})\end{array}$} & \multirow{2}{*}{$\begin{array}{l}\text { Admixture } \\
(\%)^{* *}\end{array}$} & \multirow{2}{*}{$\begin{array}{l}\text { Effective } \\
\text { water-cement } \\
\text { ratio }\end{array}$} \\
\hline & $\begin{array}{l}0-4 \\
\text { mm }\end{array}$ & $\begin{array}{l}4-10 \mathrm{~mm} \\
(\mathrm{~kg})\end{array}$ & $\begin{array}{l}10-20 \\
\mathrm{~mm}(\mathrm{~kg})\end{array}$ & & $\begin{array}{l}\text { CEM I (1/2); } \\
\text { CEM III (3) (kg) }\end{array}$ & & & \\
\hline $\mathrm{CC}-1 / 2 / 3$ & 981 & 294 & 686 & - & 300 & 150 & 1 & 0.45 \\
\hline $\mathrm{RC} 25-1 / 2 / 3$ & 981 & 294 & 512 & 130 & 300 & 168 & 1 & 0.45 \\
\hline RC50-1/2/3 & 981 & 294 & 342 & 261 & 300 & 183 & 0.9 & 0.45 \\
\hline $\mathrm{RC} 100-1 / 2 / 3$ & 981 & 294 & - & 528 & 300 & 213 & 0.9 & 0.45 \\
\hline
\end{tabular}

*1: series 1 (concrete produced with CEM I 42.5 SR and freshwater); 2: series 2 (CEM I 42.5 SR and seawater; 3: series 3 (CEM III /B 42.5 L/SR, sea water)

** The $\%$ is given with respect to weight of cement 
Table 5. Densities, water absorption and porosity test results of concrete mixes

\begin{tabular}{|l|c|c|c|}
\hline $\begin{array}{c}\text { Concrete } \\
\text { Reference }\end{array}$ & Dry density (kg/dm $\left.{ }^{\mathbf{3}}\right)$ & Water absorption (\%) & Porosity (\%) \\
\hline \multicolumn{4}{|c|}{ PHASE 1 concretes } \\
\hline CC-1 & 2.39 & 3.77 & 9.02 \\
\hline RC25-1 & 2.37 & 4.43 & 10.50 \\
\hline RC50-1 & 2.27 & 5.40 & 11.82 \\
\hline RC100-1 & 2.19 & 5.55 & 12.59 \\
\hline CC-2 & 2.39 & 3.79 & 9.04 \\
\hline RC25-2 & 2.34 & 4.43 & 10.36 \\
\hline RC50-2 & 2.29 & 5.17 & 11.85 \\
\hline RC100-2 & 2.20 & 6.57 & 14.46 \\
\hline & & 2.39 & 5.79 \\
\hline CC-3 & 2.43 & 2.76 & 6.57 \\
\hline RC25-3 & 2.38 & 3.21 & 7.20 \\
\hline RC50-3 & 2.35 & 3.24 & 7.62 \\
\hline RC100-3 & 2.24 & &
\end{tabular}


Table 6. Mechanical and durability test results of concrete mixes

\begin{tabular}{|c|c|c|c|c|c|c|c|}
\hline & \multicolumn{4}{|c|}{ Mechanical properties } & \multicolumn{3}{|c|}{ Durability Properties } \\
\hline \multirow{2}{*}{$\begin{array}{l}\text { Concrete } \\
\text { Reference }\end{array}$} & \multicolumn{2}{|c|}{$\begin{array}{c}\text { Compressive } \\
\text { strength (MPa) }\end{array}$} & \multirow{2}{*}{$\begin{array}{c}\text { Splitting tensile } \\
\text { strength (MPa) } \\
28 \text { days }\end{array}$} & \multirow{2}{*}{$\begin{array}{l}\text { Modulus of } \\
\text { elasticity } \\
\text { (GPa) } \\
28 \text { days }\end{array}$} & \multirow{2}{*}{$\begin{array}{c}\text { Sorptivity } \\
\text { coefficient } \\
\left(\mathbf{m m} / \mathbf{m i n}^{1 / 2}\right) \\
28 \text { days }\end{array}$} & \multirow{2}{*}{$\begin{array}{l}\text { charge } \\
\text { passed Cl- } \\
\text { penetration } \\
\text { (C) } 28 \text { days }\end{array}$} & \multirow{2}{*}{$\begin{array}{c}\text { Electrical } \\
\text { resistivity } \\
(\Omega * \mathrm{~cm}) \\
28 \text { days }\end{array}$} \\
\hline & 7 days & 28 days & & & & & \\
\hline \multicolumn{8}{|c|}{ PHASE 1 concretes } \\
\hline $\mathrm{CC}-1$ & 42.13 & 48.14 & 4.04 & 38.29 & 0.045 & 3483 & 6868 \\
\hline RC25-1 & 37.56 & 39.09 & 3.51 & 34.87 & 0.049 & 4889 & 6485 \\
\hline RC50-1 & 34.55 & 42.86 & 3.4 & 31.79 & 0.071 & 4282 & 5426 \\
\hline RC100-1 & 27.41 & 34.89 & 2.9 & 26.13 & 0.068 & 5040 & 5386 \\
\hline$\overline{\mathrm{CC}-2}$ & 40.23 & 50.39 & 3.41 & 37.81 & 0.030 & 2904 & 4039 \\
\hline RC25-2 & 41.72 & 47.8 & 3.39 & 35.52 & 0.040 & 4059 & 3461 \\
\hline RC50-2 & 35.75 & 42.78 & 3.24 & 32.48 & 0.052 & 3694 & 3151 \\
\hline RC100-2 & 26.13 & 36.03 & 3.03 & 28.5 & 0.045 & 9638 & 2547 \\
\hline \multicolumn{8}{|c|}{ PHASE 2 concretes } \\
\hline CC-3 & 51.63 & 55.87 & 5.15 & 47.04 & 0.022 & 963 & 17719 \\
\hline RC25-3 & 42.96 & 60.33 & 4.45 & 39.75 & 0.030 & 1235 & 15791 \\
\hline RC50-3 & 40.35 & 50.58 & 4.19 & 35.24 & 0.038 & 1321 & 17185 \\
\hline RC100-3 & 32.55 & 46.26 & 4.16 & 33.50 & 0.039 & 1171 & 14688 \\
\hline
\end{tabular}




\section{LIST OF FIGURES}

Figure 1. Particle size distribution of the three natural aggregates and the recycled mixed aggregate

Figure 2. Grading distribution of mixed fractions in different concretes

Figure. 3. Permeable porosity seawater mixed concretes in comparison to those mixed using fresh water

Figure. 4. Comparison of relative compressive strength between concretes produced with RMA and those of conventional concrete. (in each series of concretes (at 28 days)

Figure 5. Capillary water absorption of concrete mixtures. 


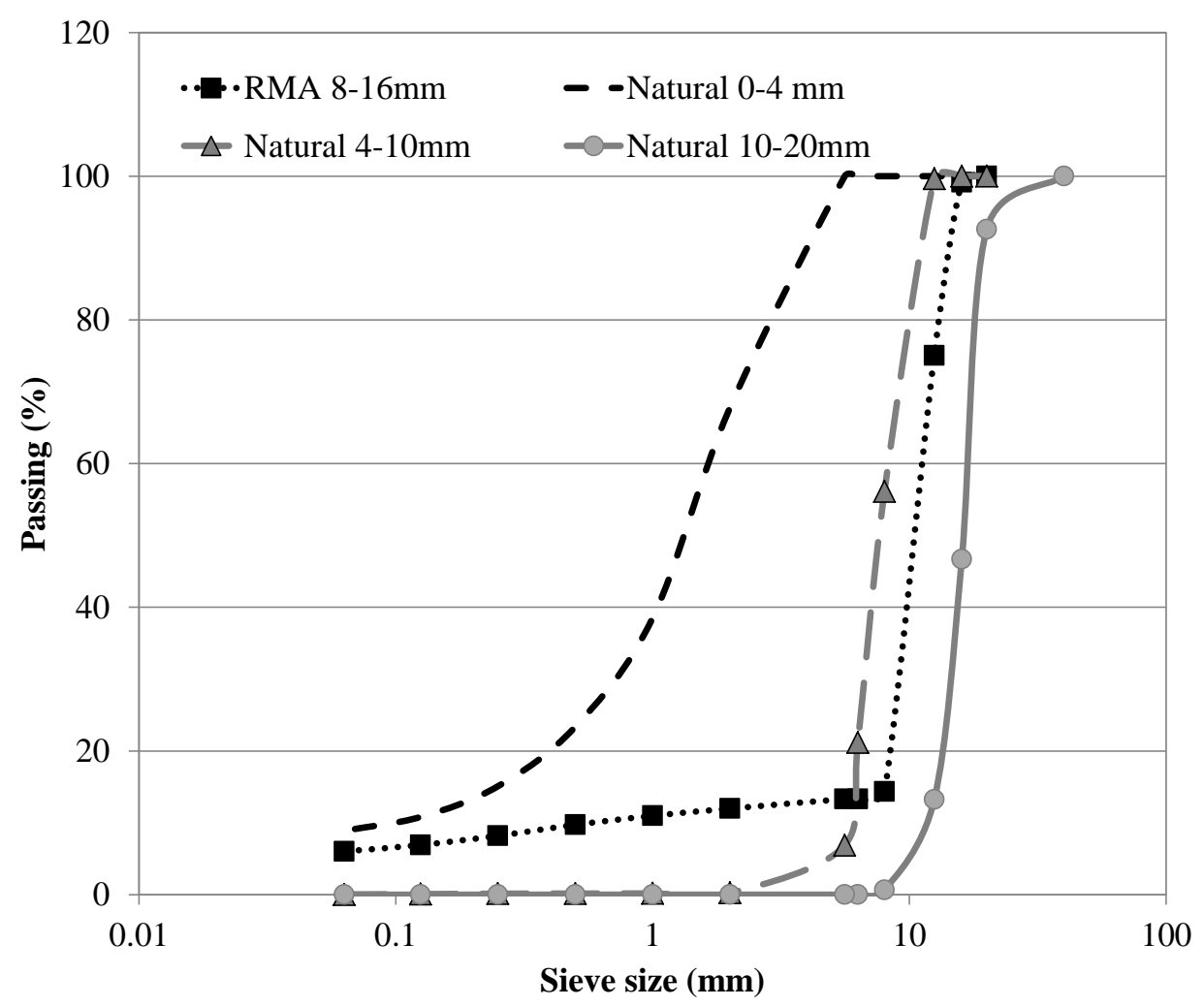

Figure 1. Particle size distribution of the three natural aggregates and the recycled mixed aggregate

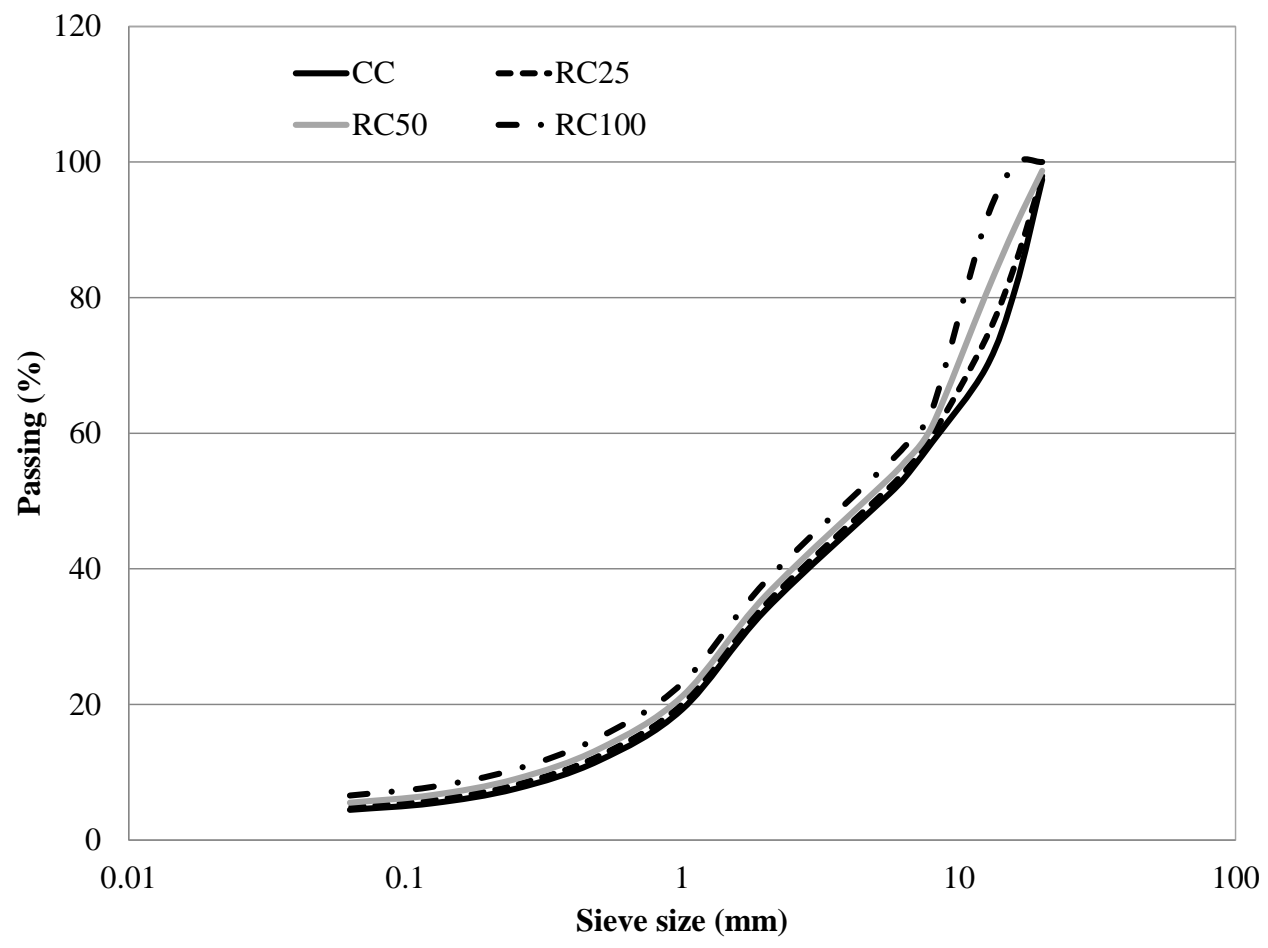

Figure 2. Grading distribution of mixed fractions in different concretes 


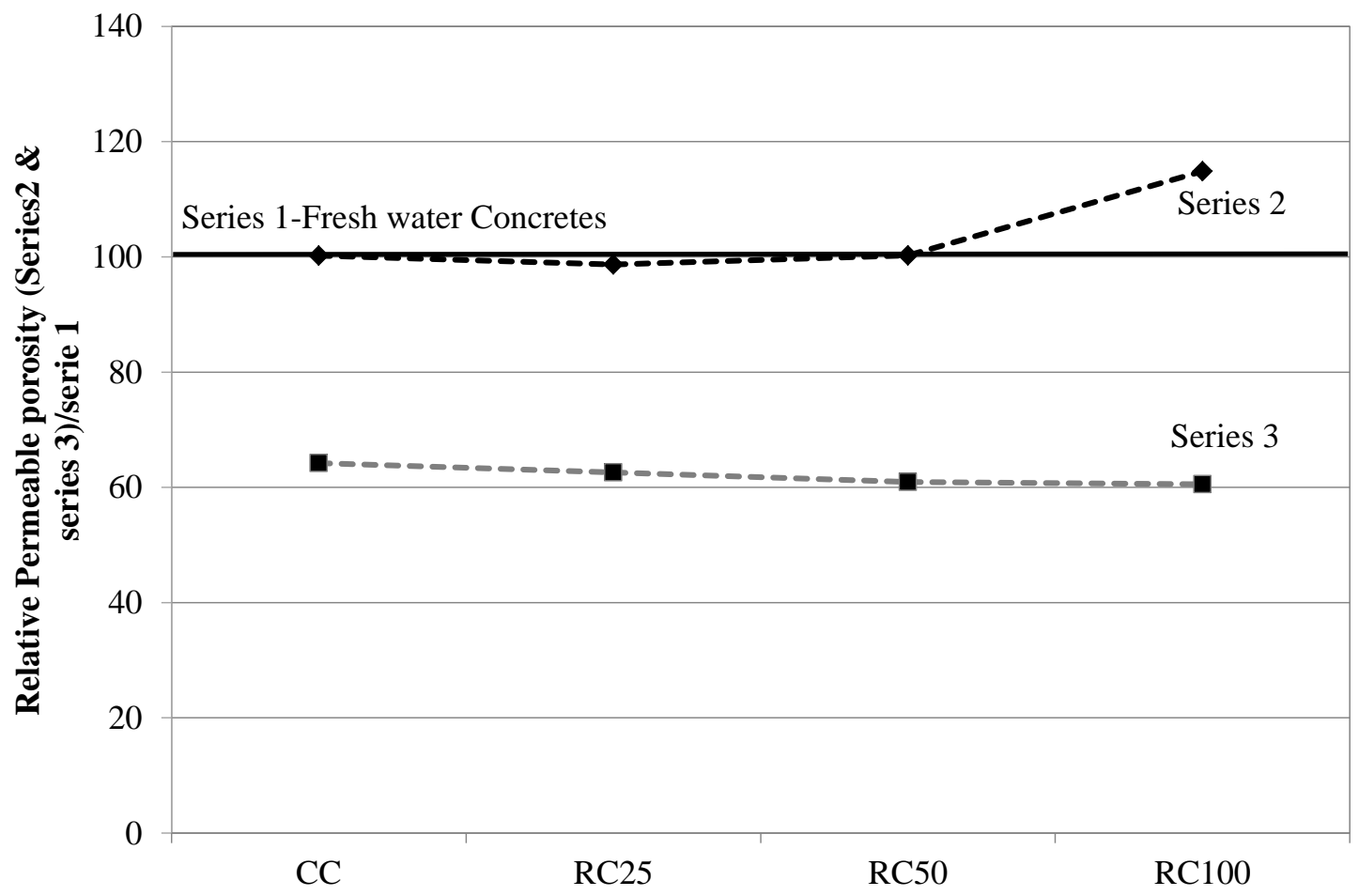

Fig. 3. Permeable porosity seawater mixed concretes in comparison to those mixed using fresh water

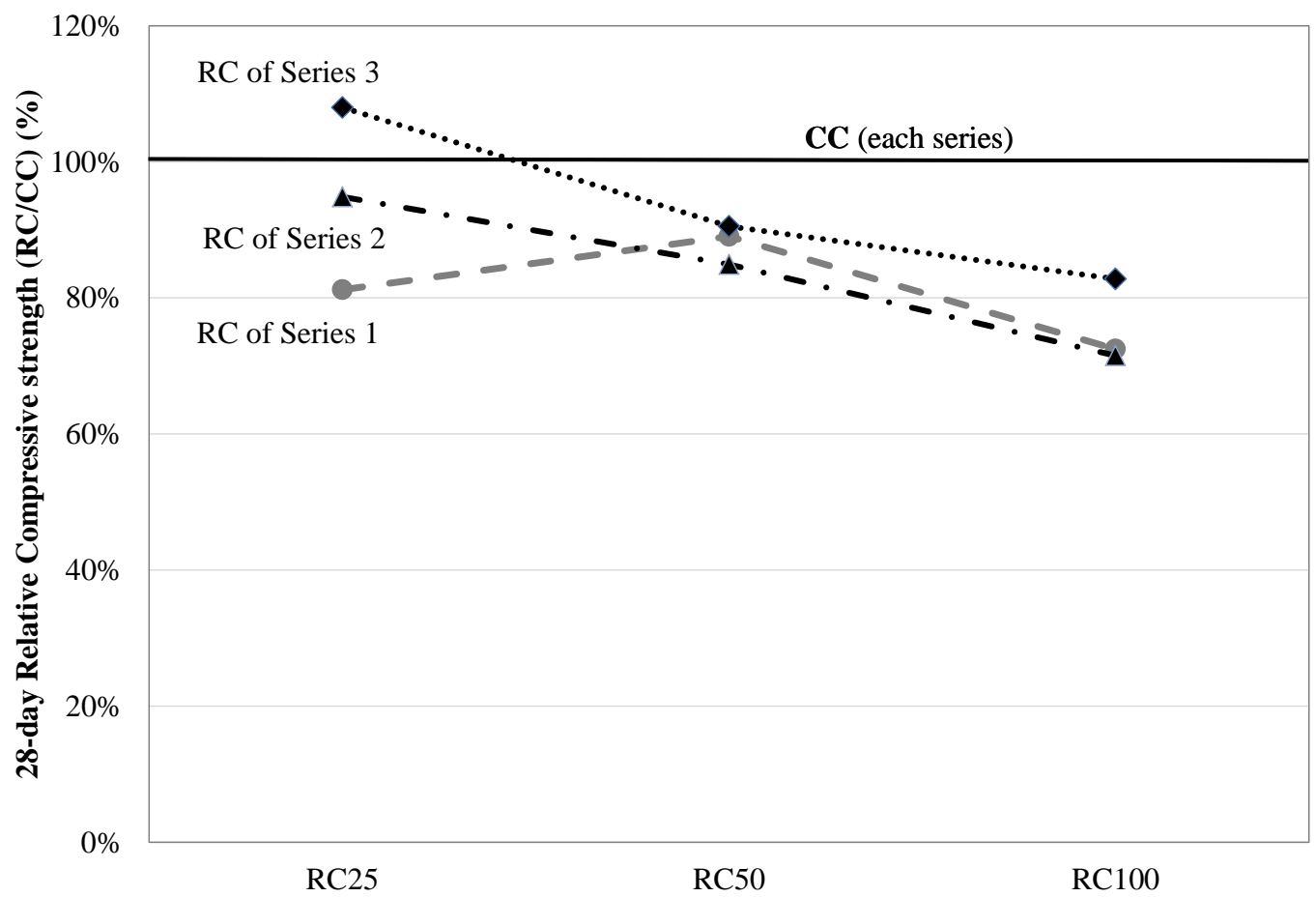

Fig. 4. Comparison of relative compressive strength between concretes produced with RMA and those of conventional concrete. (in each series of concretes (at 28 days) . 


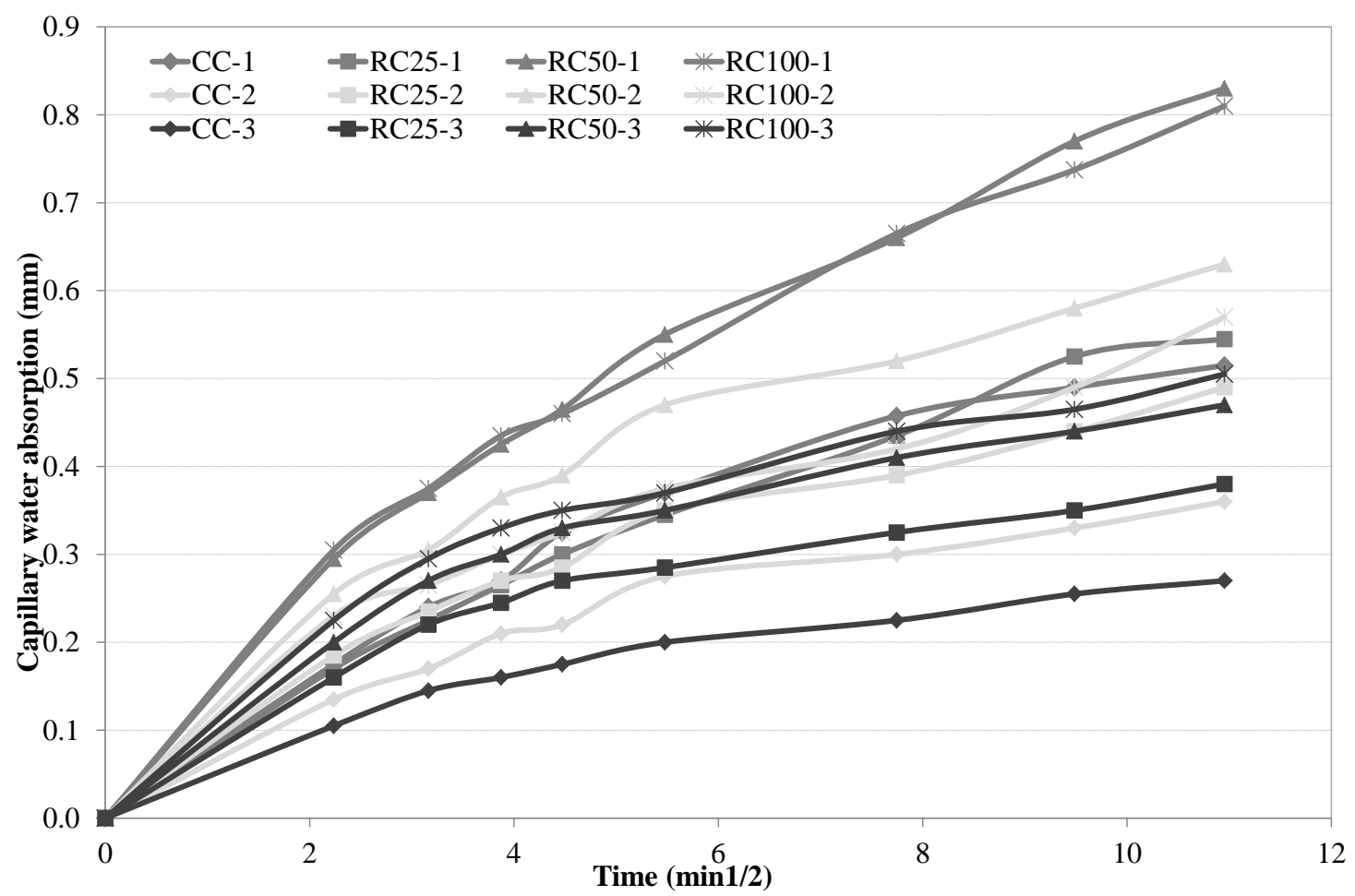

Figure 5. Capillary water absorption of concrete mixtures. 


\title{
Properties of plain concrete produced employing recycled aggregates and sea water
}

\section{Highlights:}

The use of Recycled Mixed Aggregates (RMA) leads to a reduction of landfills growth

The use of seawater represents another advance in sustainability by reducing fresh water consumption Analysis of the possibility of using RMA and seawater in the production of concrete to be used in port sites

The use of seawater in concretes with type III cement produced a denser cement matrix, which suffered low decrease by RMA addition.

\begin{abstract}
The generation of construction and demolition waste (C\&DW) is a noteworthy environmental and economic concern. The development of new applications in which Recycled Mixed Aggregates (RMA) can be used will lead to a reduction of landfills growth. Moreover, the use of seawater shall represent another advance in sustainability due to the consequent reduction of fresh water consumption, which can be a limited resource in certain areas. Although seawater is not generally recommended for concrete production, especially in reinforced concretes, seawater could be a viable replacement for fresh water in the production of plain concretes. This study intends to analyse the possibility of using RMA and seawater in the production of concrete to be used in port sites. This study is based on 3 different parameters: cement class, water source and RMA content. The results highlighted the beneficial effects of using type III cement, especially with regard to durability properties. The concretes produced employing RMA and type III cement achieved lower value of sorptivity coefficient and higher values of ultrasonic pulse velocity (UPV), chloride ion penetration resistance and electrical resistivity than those produced with natural aggregates and type I cement. Moreover the use of seawater in concretes with type III cement not only produced higher density and lower absorption capacity but also higher mechanical properties by creating a denser cement matrix, which proved to suffer low decrease by RMA addition.
\end{abstract}

Key words: mixed recycled aggregate, sea water, blast furnace cement, recycled concrete, properties

\section{INTRODUCTION}

Construction and demolition waste (C\&DW) generation is a major economic and environmental concern for European Union countries, as it represents the heaviest and most voluminous waste streams [1]. C\&DW still registers low recycling ratios, especially in Southern European countries. In these countries C\&DW is commonly comprised of several different materials such as concrete, old raw aggregates, ceramic bricks and gypsum. Following their treatment in a recycling plant the recycled aggregates sourced from this type of C\&DW are designated as recycled mixed aggregate (RMA) [2-4] [3-5]. This mixed aggregate, while being comprised of a much greater percentage of ceramic material and other impurities has comparatively only a small percentage of concrete and raw aggregates. Currently most of RMA the mixed recycled aggregates used in the construction industry are 
employed in low-strength required applications, such as road sub-base layers. fural pathways and embankments [6].

The use of RMA mixed recycled aggregate in concrete production has mainly been studied for non-structural elements $[5,6][78,9]$. Up to date, certain studies have analysed the possibility of using RMA for higher grade applications than those of non-structural concrete, such as medium-strength concrete [7] $[10,11,12]$ and high-performance concrete $[7,8][10$, 13]. The consistency of the concretes produced with RMA may be affected by the high absorption capacity of the mixed recycled aggregates, which as known is much more than that of natural aggregates [5] [8]. Therefore previous pre-wetting of the RMA is essential in order to maintain the similar fresh concrete properties found in those of conventional concrete (CC) [9] [14]. An increase in the proportion of RMA leads to a decrease in the mechanical properties of the recycled concretes in their hardened state. In its hardened state, the mechanical properties of recycled concretes decrease when the proportion of RMA increases; In concretes of 25-50 MPa compressive strength, strength dropped by up to $25 \%$ when $50 \%$ of natural coarse aggregates were replaced by RMA [3,5-7] [4,7 11]. Furthermore the drop in the mechanical strength increases when the difference between the qualities of the new concrete and the old recycled aggregate increases $[5,10][8,15]$. Durability aspects are also negatively affected by more than $25 \%$ replacement of recycled aggregates [11]. Higher replacement ratios were proved to significantly decrease the durability properties to the extent of creating limitations on the exposure possibilities of concrete [7] [10].

Despite the fact that many international standards do not permit the use of seawater in concrete manufacturing, the influence of seawater as mixing water was studied. The reason why seawater should not be used in mixtures for reinforced concretes is the higher corrosion risk. However seawater can be suitable for use in plain un-reinforced concrete production [16]. Several studies agree that in comparison with concretes mixed with fresh water, concrete mixed with seawater increases early-age strength and reduces setting time [11-14] [17 20$]$. The chloride-ion content produces an acceleration of the cement setting and hardening. According to Shi et al. [15] [21] at a given age, the hydration acceleration by $\mathrm{CaCl}_{2}$ caused a higher level of cement hydrate content in seawater mixed concretes. However, long-term studies revealed contradictory conclusions concerning the influence of seawater on cement hydrate content.

It is known that the concrete may suffer chemical attack due to the action of the high quantities of dissolved chloride, sulphate, sodium and magnesium contained in seawater[16] [22]. Nevertheless according to various investigations [11,14] $[17,20]$, the concrete produced with seawater using Blastfurnace Slag (BFS) cement and a low water-cement ratio results in low permeability, thus obtaining a high resistance to chloride penetration and corrosion of reinforcing steel. Moreover the chloride binding capacity is higher in BFS cements than that observed in Ordinary Portland Cement (OPC) due to its higher alumina content which effectively results in the production of Friedel's salt $[17,18][24,25,26]$. Nishida et al. [11] [17] also found that the influence of the cement type was much greater when compared to that of mixing water in chloride diffusion.

Though, the main, underlying purpose of this study is to analyse the possibility of using recycled aggregate combined with seawater in the manufacturing of plain concrete and the consequence that would have on hardened concrete properties in comparison to those of conventional concretes (made using Portland cement, natural aggregates and fresh water). It was also decided that an analysis of this concrete's suitability for use in the construction of concrete elements such as dyke blocks on port sites (where seawater is easily accessible) should also be carried out. In order to comply with the Port of Barcelona's technical 
specifications for dyke blocks the concrete would need to have a minimum strength of $30 \mathrm{~N} / \mathrm{mm}^{2}$ and a minimum density of $2,300 \mathrm{~kg} / \mathrm{m}^{3}$.

Two experimental phases were carried out. In the first experimental phase (Phase 1) the concretes were produced using CEM I 42.5 SR (sulphate resistant Portland cement), natural aggregates coarser than $10 \mathrm{~mm}$ were substituted in volume for recycled coarse aggregates in 4 different ratios $(0 \%, 25 \%, 50 \%$ and $100 \%)$. The four concretes were produced using fresh water and sea water. In experimental phase 2 , the four concretes were produced using CEM III / B 42.5 L / SR, Type III cement, BFS cement, with four different percentages of recycled aggregates (the volume of $0 \%, 25 \%, 50 \%$ and $100 \%$ of natural aggregates coarser than $10 \mathrm{~mm}$ were replaced by recycled aggregates) using only seawater. The recycled aggregates were sourced from a local C\&DW treatment plant. The hardened concrete tests were carried out in order to analyse the influence of the recycled mixed aggregates, seawater and cement type on the physical, mechanical and durability properties of the concrete.

\section{EXPERIMENTAL PHASE}

\subsection{Materials}

\subsubsection{Water}

This study was carried out employing two types of water: fresh mains water sourced directly from Barcelona's supply network, and seawater extracted directly from the Port of Barcelona. Table 1 shows the chemical properties of both waters.

\subsubsection{Cement}

Two cement classes were used, Type I Portland cement, CEM I 42.5 SR and Type III, BFS, cement CEM III/B 42.5 L/SR, whose chemical compositions are given in Table 2. Both types of cement were selected according to the recommendations laid down by international standards and the appropriate behaviour in seawater environments as described by several authors $[11,14,16][17,20,22,23,24]$.

\subsubsection{Aggregates}

Two types of aggregates were used: natural aggregate consisting of crushed limestone aggregates divided into three size fractions (sand $0-4 \mathrm{~mm}$, gravel $4-10 \mathrm{~mm}$ and gravel 10 $20 \mathrm{~mm}$ ) and RMA aggregate sourced from Gestora de Runes de la Construcció SA, a local C\&DW treatment plant situated in Franqueses del Vallès (Barcelona).

The coarse RMA components were classified according to UNE-EN 933-11:2009 standard and the soluble sulphates content was determined according to UNE-EN 1744-1:2010 standard. The composition of the recycled mixed aggregates were defined: concrete $57.3 \%$; bricks and tiles $22.61 \%$; natural aggregates $12.55 \%$; asphalt $5.26 \%$; gypsum $1.76 \%$; plastic and glass $0.5 \%$. The percentage of impurities such as asphalts, gypsum, plastic and glass, was relatively low, representing only $7.5 \%$ of the total amount. However, the non-predominance of any concrete or ceramic aggregates does not permit it to be classified in any of the categories accepted by the majority of international standards, consequently the recycled aggregates employed were classified as RMA [2-4] [3 5]. Although the percentage of gypsum was rather insignificant compared to that of the total materials forming the aggregate, the soluble sulphates content was quite high of $1.47 \%[3,19][4,27,28]$, and this could have an 
influence with respect to the concrete's durability. Never the less, according to previous research work carried out by authors [20] [29] concretes produced using Sulphate resistant Portland cement, Type I, and BFS cement Type III combined with this type of mixed recycled aggregates was not affected by loss of durability.

The Particle size distributions of both types of aggregates were determined according to UNEEN 933-1:2012, and their grading distribution (see Figure 1) was found to be acceptable for concrete production. The RMA aggregates described had a grading fraction of 8-16 mm which was defined as having a lower nominal diameter than that of the natural aggregates (20mm). However, according to tests carried out in previous work [20] [29], the mixed recycled aggregates' $20 \mathrm{~mm}$ of nominal size, as well as their flat shape (ceramic materials) influenced on greatly reducing the mechanical properties of the concretes. Therefore Consequently the use of a slightly lower nominal size can also be considered as recommendable for employing that type of aggregate in concrete production.

The physical and mechanical properties of each aggregate were characterized. The density and water absorption were determined according to UNE-EN 1097-6:2001, tests on the abrasion resistance and flakiness index were carried out following UNE-EN 1097-2:2010 and UNE-EN 933-3:2012, respectively. The RMA presented lower density and higher water absorption capacity than those of natural aggregates. The flakiness index and abrasion resistance (defined by Los Angeles index) of the RMA were also higher than those of the natural aggregates, the reason for this being the ceramic and old mortar attached to the concrete particles (see Table 3). The RMA characterization did not differ from those found by other authors when using RMA with similar compositions [3] [4,28].

\subsubsection{Admixture}

The admixture used in concrete production was Glenium Sky 549. This admixture is a superplastizicer water-reducer, which has a density of $1,056 \mathrm{gr} / \mathrm{cm}^{3}$, based on polycarboxylates.

\subsection{Concrete production}

Concrete production was divided into two phases. In phase 1, all concretes were produced using Portland Cement CEM I 42.5 SR. Two series, Series 1 and Series 2, of concrete production were carried out using freshwater and sea water, respectively. In phase 2, a series (Series 3) of concrete production was carried out using BFS cement CEM III/B 42.5L /SR and seawater. In each series, four recycled mixed aggregates ratios $(0 \%, 25 \%, 50 \%$ and 100\%) were used to substitute the natural aggregates $(>10 \mathrm{~mm})$.

The mix proportion of the concrete produced with $0 \%$ of recycled aggregates (CC concrete) was created employing $300 \mathrm{~kg}$ of cement and a total water-cement ratio of 0.50 . The total volume of aggregates was formed using $50 \%$ of fine aggregates, with a fraction of $0-4 \mathrm{~mm}$, and $50 \%$ of coarse aggregates. The volume of coarse aggregates (50\% of the total aggregates' volume) was formed mixing $30 \%$ of the $4-10$ fraction and the $70 \%$ of the $10-20 \mathrm{~mm}$ fraction aggregates. The recycled aggregate concretes, RC25, RC50 and RC100 were produced replacing volume of $25 \%, 50 \%$ and $100 \%$, respectively, of the natural aggregates (fraction 10$20 \mathrm{~mm}$ ) for recycled aggregates. Figure 2 shows the grading distribution of the four concretes produced. The concretes produced employing a higher percentages of recycled aggregates achieved a finer total grading distribution as a result of the finer fraction within the RMA (see Figure 1). 
As mentioned above, the total water-cement (w/c) ratio was set at 0.5 for the $\mathrm{CC}$ concrete. The effective water-cement ratio of the $\mathrm{CC}$ concrete was determined (being the ratio between the effective water weight, which would react with cement, and the cement weight used for the concrete production) and fixed at a constant value for all concretes with 0.45 . Neville [16] [22] defined the effective water in the concrete mix as the amount of water which occupies the space outside the aggregate particles. It was considered that the fine and coarse aggregates, which were used in dry condition, absorbed $80 \%$ and $20 \%$ water respectively, at concrete production. Those values were the water absorption capacity of aggregates submerged in water up to $30 \mathrm{~min}$ [8] [13]. The moisture conditions of the recycled aggregates were intensively controlled in all the concretes produced in order to obtain the same effective water ratio. The Recycled mixed aggregate was used with approximately $80 \%$ humidity, in order to avoid bleeding or water surface layers influencing the mechanical properties of the concrete [9] [14], and their effective absorption capacity was registered as 70\%. The total water amount of the concrete was considered as the amount of effective water weight plus the moisture (or absorbed water) of the aggregates (see Table 4).

Table 5 shows the mix proportioning used as well as the admixture amount used to achieve fluid consistencies, between $100-150 \mathrm{~mm}$ in the concrete slump test (S3 class following the EN 206-1:2000 standard).

The mechanical properties (compressive and splitting tensile strength and modulus of elasticity) and the resistance to chloride ion penetration were tested via the use of 15 cylindrical $(100 \varnothing \times 200 \mathrm{~mm})$ concrete specimens for each concrete mixture. The density, water absorption, porosity, capillary water absorption, Ultrasonic Pulse Velocity (UPV)-and electrical resistivity were tested via the use of $100 \mathrm{~mm}$ cubic specimens. The UNE EN 123902:2001 standard was followed for the production and curing of the concrete specimens. Concrete specimens were manually compacted using a metal rod and the specimens were covered with a plastic sheet and kept at air-curing for the first 24 hours. After 24 hours of casting, the specimens were de-moulded and then stored in a humidity room, at $21^{\circ} \mathrm{C}$ and $95 \%$ humidity, until the test ages were reached.

\subsection{Tests of on hardened concrete properties}

\subsubsection{Physical properties}

Density, water absorption and permeable porosity test 
The density, absorption and permeable porosity were measured at 28 days following the ASTM C 642-97 "Standard Test Method for Density, Absorption and Voids in Hardened Concrete'. Three cubic specimens were used in this test for each concrete mixture produced.

\subsubsection{Mechanical properties}

Compressive and splitting tensile strengths and modulus of elasticity

In each case the compressive strength, splitting tensile strength and modulus of elasticity were tested for each concrete mixture via the use of three $100 \varnothing \times 200 \mathrm{~mm}$ cylindrical specimens. The mechanical properties of the concrete studied were determined using a compression machine with a loading capacity of $3000 \mathrm{kN}$. The compressive strength was measured at the ages of 7 and 28 days following UNE-EN 12390-3:2009 specifications. The splitting tensile strength and modulus of elasticity were tested after 28 days of casting following the UNE-EN 12390-6:2010 and UNE-EN 12390-13:2014 specifications, respectively.

\subsubsection{Durability properties \\ Capillary water absorption}

The capillary water absorption, which was carried out in accordance with ISO 15148:2002(E), was assessed at 28 days after casting via the use of the $100 \mathrm{~mm}$ cubic concrete specimens. For sorptivity determination, the specimens were previously oven-dried at $40^{\circ} \mathrm{C}$ until constant weight. The bottom face of each of the specimens was immersed in water to a depth of a $5 \mathrm{~mm}$ (the lateral surfaces of the specimens were coated with impermeable resin). The cumulative water absorbed was recorded at different time intervals up to $120 \mathrm{~min}$ by weighing the specimens after removing the surface water using a dampened cloth. The sorptivity coefficient was calculated as the slope of the regression curve of the quantity of water absorbed by a unit surface area versus the square root of the elapsed time from the initial instant up to $120 \mathrm{~min}$. The data detailing the capillary water absorption are the results of the average obtained from three measurements taken.

\section{Chloride ion penetration test}

The test of chloride penetrability of concrete was conducted in accordance with ASTM C1202-12 specifications via the use of $100 \varnothing \times 50 \mathrm{~mm}$ concrete discs cut from the middle of two different $100 \varnothing \times 200 \mathrm{~mm}$ concrete cylinders. The resistance of the concrete to chloride ion penetration is represented by the total charge passed in Coulombs during a test period of 6 $\mathrm{h}$. In this study, the chloride ion penetrability test was carried out on concrete specimens at the ages of 28 days and each result was the average of two measurements.

\section{Electrical resistivity}

The electrical resistivity test was carried out after 28 days of casting via the use of $100 \mathrm{~mm}$ cubic specimens. Concrete resistance was measured in the laboratory with a basic electric device, the concrete specimens being in a saturated surface-dry condition. The measurements were carried out using an electric conductive gel spread on the contact surfaces, the copper plates being used as cathodes. Low-resistance contact between the concrete and the measurement circuit is critical in obtaining an accurate measurement. The strength applied on the cathodes can have significant effects on field resistance measurements, consequently the specimens were assessed employing a fixed weight at the same position upon the cathodes. The voltage and current across a sample of known dimensions were measured and the resistivity was determined. All specimens were tested at 28 days and each result was the average of 3 measurements taken. 


\section{RESULTS AND DISCUSSION \\ 3.1 Physical properties}

\section{Dry-density, water absorption and permeable porosity test}

The results obtained in the tests carried out on dry-density, water absorption and permeable porosity are shown in table 5 . The $100 \%$ substitution of natural aggregates $(>10 \mathrm{~mm})$ for recycled aggregates produced a decrease in concrete density of $9 \%$, while concretes with $50 \%$ and $25 \%$ showed dry-density drops of $4 \%$ and $2 \%$ respectively. Concrete density is highly dependent on the density of the recycled aggregates used, a fact which has been stated by several authors $[3,8][4,13,30]$. In our studies the reduction encountered was in accordance with the data given on reductions in other studies $[6,8][9,12,13]$ (between $8-12 \%$ ) using RMA in high replacement ratios.

According to the results on concretes produced in Phase 1, the use of fresh or sea water did not have any negative influence on the physical properties of the four types of concretes. The concretes from series 3 showed slightly higher densities to those from phase 1 for a given RMA replacement ratio. Probably as a result of a denser cement paste.

The Technical Requirements Specification of the Port of Barcelona indicates that the concrete blocks must have a minimum density of $2.30 \mathrm{~kg} / \mathrm{dm}^{3}$. All the conventional concretes $(\mathrm{CC}-1$, CC-2 and CC-3) plus the 25\% recycled aggregate concretes of series 1, 2 and 3 (RC25-1, RC25-2 and RC25-3) met that requirement. In series 3 concrete a maximum of 50\% of RMA (RC50-3) could be allowed for dyke block production. The use of 50\% of RMA employing Portland cement for concrete production is possible when $50 \%$ of the aggregates are mixed together with 50\% steel slag aggregates [21] [31].

Water absorption and permeable porosity followed similar tendencies to those of the density property, the increase in RMA replacement produced an increase in water absorption and porosity. The lowest values were found to be in concretes produced with cement type III, series 3, due to its pozzolanic reactions. It is widely accepted that the use of BFS cement as a partial replacement of ordinary Portland cement creates a denser matrix and reduces permeability and porosity $[22,23][32,33,34]$. Moreover Kou et al. found that the use of BFS cement contributed to performance improvement in concretes produced with recycled aggregate, this performance being lower in conventional concretes [24] [35].

Figure 3 shows the relation between the amount of accessible pores in concretes produced with sea water in series 2 and 3 with respect to the amount of accessible pores in the corresponding concrete type produced with fresh water.

As mentioned previously, when type I cement was employed the concretes produced with sea or fresh water achieved similar accessible pores.

The concretes produced with type III cement and sea water achieved much lower permeable porous than concretes produced employing Portland cement. Moreover, the concretes produced employing BFS cement and recycled aggregates achieved a higher reduction of porosity than those produced with Portland cement (see Fig. 3). The mentioned difference in levels of porosity was probably a consequence of a pozzolanic reactivity and higher densification of cement paste caused by the fine material in the RMA [25] [36, 37, 38]. Also Mohammed et al. [13] [19] argued that the deposition of ettringite and Friedel's salt in concrete's air voids caused by diffused sulphates and chlorides also contributed to cement matrix densification. 
The higher initial porosity of RMA produced higher reductions as a result of the seawater being absorbed by the aggregates, which may in turn contribute to the RMA pores being filled by new hydrates.

\subsection{Mechanical properties}

\subsubsection{Compressive strength}

Table 6 shows that, in each series of concrete fabrication, the use of RMA not only decreases the mechanical properties of compressive and splitting tensile strength but also the modulus elasticity of concretes when compared to those of conventional concrete. According to the concretes produced in Phase 1, the concretes produced with sea water achieved similar compressive strength to that of the corresponding concrete produced with fresh water. Moreover, the influence of the sea water was similar in concretes produced with natural and recycled aggregates. RC100-1 and RC100-2 had 27.5\% and 28.5\% of compressive strength reductions with respect to that of $\mathrm{CC}-1$ and $\mathrm{CC}-2$ respectively at 28 days. Mas et al. [5] [8] and Martinez-Lage et al. [6] [9] found similar compressive strength reductions when RMA was used to replace natural aggregates.

The compressive strength of CC, RC25, RC50 and RC100 concretes produced at series 3 was $11 \%, 26 \%, 20 \%$ and $28 \%$ respectively, proving to be higher than that of those concretes produced at series 2. The influence of the recycled aggregates on the reduction of the compressive strength was lower in series 3 than that in series 1 and 2. RC100-3 achieved $17 \%$ lower compressive strength than that of $\mathrm{CC}-3$, which proved to be lower than the concretes produced with Portland Type I cement. The increase of pozzolanic reactions within recycled aggregates has been noted in many studies [24,26] [35,39,40].

The concretes produced with recycled aggregates achieved a higher increase of compressive strength from 7 to 28 days of age. The concrete produced with $100 \%$ of RMA showed an increase of between 20-42\% (in different series) and CC concretes achieved an increase of between 6- 25\%. This increase was in all probability due to the reaction of the binder components with fine material inherent in the RMA.

The Port of Barcelona's Technical Requirements Specifications stipulated a minimum of 30 MPa of compressive strength. All concretes satisfied that prescribed limit at 28 days of age (see Table 6).

Figure 4 shows the ratio of compressive strength of the recycled aggregate concrete with respect to that of conventional concrete in each series. The recycled concretes made in series 3 showed a lower decrease of compressive strength with respect to that of CC concrete when compared to recycled concretes produced in series 1 and series 2 .

\subsubsection{Splitting tensile strength}

As depicted in table 6, the splitting tensile strength of concretes decreased in accordance with the higher amount of recycled aggregates employed in concrete production. According to previous work carried out by authors [20] [29], the $20 \mathrm{~mm}$ nominal size of RMA mixed recycled aggregates as well as their flat shape influenced in the obtaining of lower splitting tensile strength. However, it is also known that the concretes produced employing recycled concrete aggregates can improve the splitting tensile strength of concrete $[26,27][1,40]$. With 
respect to phase 1 , the concretes produced in series 2 (with sea water) achieved a slightly lower strength than those of the corresponding concretes in series 1 .

The concretes produced in series 3, which employed type III cement and seawater, achieved the highest strength. Although, the splitting tensile strength of concretes produced with RMA decreased, the concretes of series 3, even with a replacement of $100 \%$ of RMA, achieved higher values than those of CC concretes produced in any of series 1 or series 2 .

\subsubsection{Modulus of elasticity}

The RMA replacement produced modulus of elasticity reductions for given cement and water types throughout all the series produced (see Table 6). The reduction of modulus of elasticity is proportional to the modulus of elasticity of the aggregates [28] [AA], which in turn depends on its density, a fact exposed by Lydon and Balendran [29] [42]. The use of RMA in concrete production results in a reduction of the concrete's modulus elasticity. The modulus of elasticity of concretes containing 100\% RMA was observed to decline in average values, ranging from $25 \%$ to $32 \%$. These reductions were in accordance with those results determined by Martinez-Lage et al. [6] [9] and Gonzalez-Corominas and Etxeberria [8] [13] in concretes produced with high replacement ratios of RMA. The results were similar to those of the other mechanical properties tested, in as far as the use of seawater did not influence the modulus of elasticity of concretes produced with type I cement.

It was determined that series 3 concretes, produced with type III cement and seawater achieved the highest modulus of elasticity. The reason for this being a higher development of the cement matrix hydration as was observed in the density and permeable pore test.

\subsection{Durability properties}

\subsubsection{Capillary water absorption}

The results of assessing the concrete specimens' capillary water absorption over a period of 120 min are shown in Figure 5. The capillary water absorption of concretes produced with RMA showed much higher values than those of conventional concretes, throughout all the concrete series, this was probably due to the connectivity of the porous in each grain of the coarse mixed aggregate, a fact which has also been reported by other researchers $[30,31][43$, $44,45]$.

According to the results achieved by concretes produced in Phase 1 (with Portland Cement), the use of sea water reduced the capillary absorption capacity of concretes produced with high percentages of recycled aggregates, probably due to the presence of more mineral salts within the chemical composition of that water and consequently in the pores of aggregates and cement paste. The capillary absorption capacity of concretes produced with Portland cement was higher than those produced with Type III BFS Cement. The pozzolanic activity of slag reduces capillary water absorption as a result of the increase of density of cement porous structure due to the formation of the secondary CSH gel, which fills capillary pores [32] $[46,47]$. The correlation coefficients of each of the concretes curves values were determined. The concretes produced with cement Portland obtained a value between 0.95 and 0.97. The correlation coefficient of the concretes produced employing type III BFS cement was between 0.92 and 0.95. There was not difference between CC and RC concretes.

The sorptivity results (see Table 6) showed that the series 3 concretes produced employing $100 \%$ of RMA had a lower sorptivity coefficient when compared to those from the natural aggregate concrete produced with type I cement. The present sorptivity findings are consistent with the observations reported by other authors [33] [11,48]. Moreover, the results met the 
boundaries laid down by Menedez et al. [34] [49] of $0.39 \mathrm{~mm} / \mathrm{min}^{1 / 2}$, to be considered as a durable concrete on the basis of its serptivity coefficient. According to Neville [16]-[22], concretes produced with the water/cement ratio of 0.4 and 0.6 achieve sorptivity values of $0.09 \mathrm{~mm} / \mathrm{min}^{0.5}$ and $0.17 \mathrm{~mm} / \mathrm{min}^{0.5}$, respectively.

\subsubsection{Chloride ion penetration}

Table 6 shows the amount of electric flux through the concrete specimens at 28 days of age, indicating the resistance to chloride ion penetration of the specimens.

According to the results obtained from the concretes produced in Phase 1, the use of mixed recycled aggregates RMA decreased the resistance to chloride ion penetration, a fact which has also been detected in other works [20] [29]. Only the conventional concretes of series 1 and 2 were classified as possessing moderate chloride penetrability.It was also determined that the use of sea water in series 2 concrete production considerably reduced the resistance of chloride ion penetration in concrete produced with $100 \%$ of recycled aggregates.

All concrete mixed with type III cement displayed a total charge passed value of between 800 and 1400 coulombs, which is defined according to the classifications of the testing method as corresponding to a very low or low to ion chloride penetrability. According to these results, the electric flux decreased when the concretes were mixed employing type III cement, indicating that BFS content improved the chloride resistance of concrete by improving its impermeability and chloride binding capacity, which has been previously reported in other studies $[23,34,35][34,53,54]$. The beneficial influence of BFS in chloride resistance of concretes was clearly observed, nevertheless the reduction of chloride ion penetration noted by Shi et al. [15] [21] when combining metakaolin with seawater was not discovered when using BFS.

Although the use of RMA in concrete production had a negative influence on the resistance of chloride ion penetration. In series 3 concrete, the electric flux recorded in the concretes with $100 \%$ of RMA was $60 \%$ lower than that of the conventional concrete from series 2 and series 1 , which highlights the beneficial influence of BFS in cements where durability is concerned.

\subsubsection{Electrical resistivity}

Table 6 shows that the electrical resistivity of concretes (they were saturated with water) decreased when higher percentages of recycled aggregates were used for concrete production. Mixtures from series 1 and 2, produced with type I cement had a high and very high corrosion risk, respectively. The use of seawater reduced electric resistance between 41-61\% with respect to electric resistance of concretes with the same RMA replacement ratio.

It can be observed that concretes produced with type III cement showed significant higher resistance to electric flux. The porosity refinement, due to the pozzolanic hydration enhancement, increased the electrical resistance to between $78-88 \%$ of those concretes produced with type I cement for a given RMA replacement ratio and water type. Concretes made with $100 \%$ of RMA from series 3 showed a significantly higher value than those of conventional concretes from series 1 and 2. According to Langford and Broomfield [36] [55], the mixes from series 3 , produced with type III cement, showed low and moderate corrosion risk, respectively. 
These results, as other researchers have already confirmed [11] [17], endorse the fact that it is in reality the cement type that is the major influence on electrical resistivity, playing an active part above that of the replacement ratio of RMA or the water type used.

\section{CONCLUSIONS}

The following conclusions can be drawn from the results of this study:

- The results of a comparative study between conventional concrete and recycled aggregate concrete, which employed the same type of cement and water, concluded that the concrete produced employing recycled coarse mixed aggregates in substitution of natural aggregates resulted in a reduction of density, mechanical and durability properties.

- The reduction of density and mechanical properties of concretes produced employing up to $50 \%$ of RMA was lower than $5 \%$ and $15 \%$ respectively in comparison to those values of $\mathrm{CC}$ concretes. However, the absorption and durability properties values of concretes produced using up to $50 \%$ of MRA doubled the values obtained by the CC concretes.

- The porosity and permeability of RMA had an influence on the reduction of the values of those properties. However, comparative tests of the permeable porous between RMA concretes produced with fresh water and those of sea water showed that the use of sea water in the production of the RMA concretes improved the obtained values in durability.

- The concretes produced with BFS cement and sea water achieved the highest values of mechanical and durability properties. The influence of RMA was lower than those found in concretes produced with Portland cement.

- The concretes produced employing up to $100 \%$ of recycled coarse aggregates using type III blast furnace slag cement and sea water, achieved more adequate durability properties than those of conventional concrete produced employing Portland cement, freshwater and raw aggregates.

For the production of plain concrete elements such as dyke blocks in port areas (minimum of $2.3 \mathrm{~kg} / \mathrm{dm} 3$ of density and $30 \mathrm{MPa}$ of compressive strength are required) a $25 \%$ maximum of recycled aggregates should be employed when Portland cement is being used with fresh or sea water. However, a suitable concrete could be produced using $50 \%$ of recycled aggregate when Type III Blast furnace slag cement and sea water are employed together. The density of the concrete being the limiting property.

In general it can be assumed that the use of recycled aggregates as well as the type of cements used for concrete production have a greater influence on the properties of plain concretes than the use of sea water. Concretes produced employing BFS cement achieved excellent properties even when they were produced using recycled aggregates and sea water. However, more experimental work needs to be carried out in order to guarantee the adequate properties and the durability of concretes.

According to physical properties:

As the RMA replacement increased not only did the density decrease but the water absorption and the permeable porosity also increased significantly with respect to those of conventional concrete, independent of the type of water and cement used. 
For the production of plain concrete elements such as dyke blocks in port areas (minimmm of $2.3 \mathrm{~kg} / \mathrm{dm} 3$ of density is required) a $25 \%$ maximmm of recycled aggregates should be employed when Portland cement is being employed with fresh or sea water. However, a suitable concrete could be produced using 50\% of recycled aggregate when Type III Blast furnace slag cement and sea water are employed.

According to mechanical properties:

The mechanical properties of compressive and tensile strength as well as modulus of elasticity decrease when higher percentages of mixed recycled coarse aggregate are used in substitution of natural aggregates in concretes produced employing Portland cement with sea er freshwater.

Concretes produced with Type III blast furnace slag cement and sea water achieved the highest strength and the influence of the recycled aggregates on the mechanical properties was lower than those found in concretes produced with Portland cement.

According to Durability properties:

An increase in the use of RMA for concrete production results in the reduction of concrete durability properties due to the increase of porosity and permeability of concrete. The use of sea water improved those properties.

The concretes produced employing up to $100 \%$ of recycled coarse aggregates using type Ill blast furnace stag cement and sea water, achieved more adequate durability properties than those of conventional concrete produced employing Portland cement, freshwater and raw aggregates.

In general it can be assumed that the use of recycled aggregates as well as the type of cements used for concrete production have a greater influence on the properties of plain concretes than the use of sea water. Concretes produced employing BFS cement achieved excellent properties even when they were produced using recycled aggregates and sea water. However, more experiments are necessary in order to guarantee the adequate properties and the durability of concretes.

\section{Acknowledgements}

The authors wish to acknowledge the financial support of The Ministry of Economy and Competitiveness of the Government of Spain (MINECO) for providing funds for the INNPACT project (IPT-2012-1093-310000) and also the European Regional Development Fund (FEDER).

\section{References}

[1] Eurostat. Waste statistics in Europe. URL: http://epp.eurostat.ec.europa.eu/, (n.d.).

[2] J. de Brito, a. S. Pereira, J.R. Correia, Mechanical behaviour of non-structurat eoncrete made with recycled ceramic aggregates, Cem. Concr. Compos. 27 (2005) 429-433. doi:10.1016/j.cemeoncemp.2004.07.005.

[2] , [3] S.C. Angulo, P.M. Carrijo, A.D. Figueiredo, A.P. Chaves, V.M. John, On the classification of mixed construction and demolition waste aggregate by porosity and its impact on the mechanical performance of concrete, Mater. Struct. 43 (2010) 519-28. 
[3], [4] F. Agrela, M. Sánchez de Juan, J. Ayuso, V.L. Geraldes, J.R. Jiménez, Limiting properties in the characterisation of mixed recycled aggregates for use in the manufacture of concrete, Constr. Build. Mater. 25 (2011) 3950-3955. doi:10.1016/j.conbuildmat.2011.04.027.

[4], [5] R.V. Silva, J. de Brito, R.K. Dhir, Properties and composition of recycled aggregates from construction and demolition waste suitable for concrete production, Constr. Build. Mater. 65 (2014) 201-217. doi:10.1016/j.conbuildmat.2014.04.117.

[6] E. Vázquez, Regarding Construction and Demolition Waste in Severat Countries, Prog. Recyc1. Built Environ. RLEM State-of the Art Reports. 8 (2013) $37-173$.

[7] B. Mas, A. Cladera, J. Bestard, D. Muntaner, C.E. López, S. Piña, et al., Concrete with mixed recycled aggregates: Influence of the type of cement, Constr. Build. Mater. 34 (2012) 430-441. doi:10.1016/j.conbuildmat.2012.02.092.

[5], [8] B. Mas, A. Cladera, T. del Olmo, F. Pitarch, Influence of the amount of mixed recycled aggregates on the properties of concrete for non-structural use, Constr. Build. Mater. 27 (2012) 612-622. doi:10.1016/j.conbuildmat.2011.06.073.

[6], [9] I. Martínez-Lage, F. Martínez-Abella, C. Vázquez-Herrero, J.L. PérezOrdóñez., Properties of plain concrete made with mixed recycled coarse aggregate, Constr. Build. Mater. 37 (2012) 171-176. doi:10.1016/j.conbuildmat.2012.07.045.

[7], [10] C. Hoffmann, S. Schubert, A. Leemann, M. Motavalli, Recycled concrete and mixed rubble as aggregates: Influence of variations in composition on the concrete properties and their use as structural material, Constr. Build. Mater. 35 (2012) 701-709. doi:10.1016/j.conbuildmat.2011.10.007.

[11] C. Medina, W. Zhu, T. Howind, M.I. Sánchez de Rojas, M. Frías, Influence of mixed recycled aggregate on the physical mechanical properties of recycled concrete, J. Clean. Prod. 68 (2014) 216 225. doi:10.1016/j.jclepro.2014.01.002.

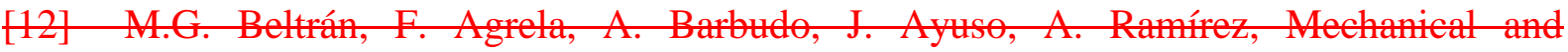
durability properties of concretes manufactured with biomass bettom ash and recycled coarse aggregates, Constr. Build. Mater. 72 (2014) 231-238. doi:10.1016/j.conbuildmat.2014.09.019.

[8], [13] A. Gonzalez-Corominas, M. Etxeberria, Properties of high performance concrete made with recycled fine ceramic and coarse mixed aggregates, Constr. Build. Mater. 68 (2014) 618-626. doi:10.1016/j.conbuildmat.2014.07.016.

[9], [14] C.S. Poon, Z.H. Shui, L. Lam, H. Fok, S.C. Kou, Influence of moisture states of natural and recycled aggregates on the slump and compressive strength of concrete, Cem. Concr. Res. 34 (2004) 31-36. doi:10.1016/S0008-8846(03)00186-8.

[10], [15] A. Gonzalez-Corominas, M. Etxeberria, Experimental analysis of properties of high performance recycled aggregate concrete, Constr. Build. Mater. 52 (2014) 227-235. doi:10.1016/j.conbuildmat.2013.11.054.

[16] S.H. Kosmatka, B. Kerkhøff, W.C. Panarese, Design and Control of Concrete Mixtures, 14th Ed., Portland Cement Association, Skokie, Hlinois, 2002.

[11], [17] T. Nishida, N. Otsuki, H. Ohara, Z.M. Garba-Say, T. Nagata, Some Considerations for Applicability of Seawater as Mixing Water in Concrete, J. Mater. Civ. Eng. 27(7) (2015) 
[12], [18] S.K. Kaushik, S. Islam, Suitability of sea water for mixing structural concrete exposed to a marine environment, Cem. Concr. Compos. 17 (1995) 177-185. doi:10.1016/0958-9465(95)00015-5.

[13], [19] T.U. Mohammed, H. Hamada, T. Yamaji, Performance of seawater-mixed concrete in the tidal environment, Cem. Concr. Res. 34 (2004) 593-601. doi:10.1016/j.cemconres.2003.09.020.

[14], [20] N. Otsuki, T. Saito, Y. Tadokoro, Possibility of Sea Water as Mixing Water in Concrete, Journal of Civil Engineering and Architecture 6 (2012) 1273-1279.

[15], [21] Z. Shi, Z. Shui, Q. Li, H. Geng, Combined effect of metakaolin and sea water on performance and microstructures of concrete, Constr. Build. Mater. 74 (2015) 57-64. doi:10.1016/j.conbuildmat.2014.10.023.

[16], [22] A.M. Neville, Properties of Concrete, 4th ed., 1995.

[23] P. Hewlett, Lea's Chemistry of Cement and Concrete, 4th ed., Butterworth Heineman, 2004.

[24] C. Arya, Y. Xu, Effect of cement type on chloride binding and corrosion of steel in eonerete, Cem. Coner. Res. 25 (1995) 893 902. doi:10.101610008 8846(95)00080 V.

[17], [25] M.V.A. Florea, H.J.H. Brouwers, Chloride binding related to hydration products, Cem. Concr. Res. 42 (2012) 282-290. doi:10.1016/j.cemconres.2011.09.016.

[18], [26] M.V. a. Florea, H.J.H. Brouwers, Modelling of chloride binding related to hydration products in slag-blended cements, Constr. Build. Mater. 64 (2014) 421-430. doi:10.1016/j.conbuildmat.2014.04.038

[19], [27] EHE. Instrucción del hormigón estructural (Spanish Concrete Structural Code), (2008).

[28] M. Martín-Morales, M. Zamorane, A. Ruiz Moyane, I. Valverde Espinøsa, Characterization of recycled aggregates construction and demolition waste for concrete production following the Spanish Structural Concrete Code EHE-08, Constr. Build. Mater. 25 (2011) 742 748. doi:10.1016/j.conbuildmat.2010.07.012.

[20], [29] M. Etxeberria; A. Gonzalez, I. Valero, Application of low grade recycled aggregates for nonstructural concrete production in the city of Barcelona, Third International Conference on Sustainable Construction Materials and Technologies set for Kyoto, Japan, August 2013

[30] D. Matias, J. de Brito, A. Rosa, D. Pedro, Mechanical properties of concrete produced with recycled coarse aggregates Influence of the use of superplasticizers, Constr. Build. Mater. 44 (2013) 101-109. doi:10.1016/j.conbuildmat.2013.03.011.

[21], [31] Miren Etxeberria, Jesus Manuel Fernandez, Jussara Limeira, Secondary aggregates and sea water employment for sustainable concrete dyke blocks production: case study, Construction and Building Materials 113 (2016) 586-595.

[32] J. Bijen, Benefits of stag and fly ash, Constr. Build. Mater. 10 (1996) 309314. doi:10.1016/0950-0618(95)00014-3.

[22], [33] C.-M. Aldea, F. Young, K. Wang, S.P. Shah, Effects of curing conditions on properties of concrete using slag replacement, Cem. Concr. Res. 30 (2000) 465-472. doi:10.1016/S0008-8846(00)00200-3. 
[23], [34] H.-W. Song, V. Saraswathy, Studies on the corrosion resistance of reinforced steel in concrete with ground granulated blast-furnace slag--An overview., J. Hazard. Mater. 138 (2006) 226-33. doi:10.1016/j.jhazmat.2006.07.022.

[24], [35] S.C. Kou, C.S. Poon, F. Agrela, Comparisons of natural and recycled aggregate concretes prepared with the addition of different mineral admixtures, Cem. Concr. Compos. 33 (2011) 788-795. doi:10.1016/j.cemconcomp.2011.05.009.

[36] J. Saliba, E. Rozière, F. Grondin, a. Loukili, Influence of shrinkage reducing admixtures on plastic and long term shrinkage, Cem. Concr. Compos. 33 (2011) 209217. doi:10.1016/j.cemconcomp.2010.10.006.

[37] M.S. Meddah, R. Sato, Effect of curing methods on autogenous shrinkage and selfinduced stress of high-performance concrete, ACI Mater. J. 107 (2010) 6574.

[25], [38] M. Pepe, E.A.B. Koenders, C. Faella, E. Martinelli, Structural concrete made with recycled aggregates: Hydration process and compressive strength models, Mech. Res. Commun. 58 (2014) 139-145. doi:10.1016/j.mechrescom.2014.02.001.

[26], [40] A. Ajdukiewicz, A. Kliszczewicz, Influence of recycled aggregates on mechanical properties of HS/HPC, Cem. Concr. Compos. 24 (2002) 269-279. doi:10.1016/S0958-9465(01)00012-9.

[27] Muzaffer Mansur Tüfekçi · Özgür Çakır, An Investigation on Mechanical and Physical Properties of Recycled Coarse Aggregate (RCA) Concrete with GGBFS, Int J Civ Eng DOI 10.1007/s40999-017-0167-x

[41] S.C. Kou, C.S. Poon, D. Chan, Influence of fly ash as a cement addition on the properties of recycled aggregate concrete, Mater. Struct. 41 (2008) 1191 201.

[28] H. Dilbas• Ö. Cakir M. Simsek, Recycled Aggregate Concretes (RACs) for Structural Use: An Evaluation on Elasticity Modulus and Energy Capacities, Int J Civ Eng (2017) 15:247-261, DOI 10.1007/s40999-016-0077-3

[29], [42] F. Lydon, R.. Balendran, Some observations on elastic properties of plain concrete, Cem. Concr. Res. 16 (1986) 314-24.

[30], [43] S.M. Levy, P. Helene, Durability of recycled aggregates concrete: a safe way to sustainable development, Cem. Concr. Res. 34 (2004) 1975-1980. doi:10.1016/j.cemconres.2004.02.009.

[44] C.J. Zega, A.A. Di Maio, Use of recycled fine aggregate in concretes with durable requirements., Waste Manag. 31 (2011) 2336 40. doi:10.1016/j.wasman.2011.06.011.

[31], [45] E. Wirquin, R. Zaharieva, F. Buyle-Bodin, Use of water absorption by concrete as a criterion of the durability of concrete - application to recycled aggregate concrete, Mater. Struct. 33 (2000) 403-8.

[32], [46] A. Hadjsadok, S. Kenai, L. Courard, F. Michel, J. Khatib, Durability of mortar and concretes containing slag with low hydraulic activity, Cem. Concr. Compos. 34 (2012) 671-677. doi:10.1016/j.cemconcomp.2012.02.011.

[47] C. Malami, V. Kaloidas, G. Batis, N. Kouloumbi, Carbenation and peresity of mertar specimens with pozzolanic and hydraulic cement admixtures, Cem. Concr. Res. 24 (1994) 1444-1454. doi:10.1016/0008-8846(94)90158-9. 
[33], [48] S.C. Kou, C.S. Poon, H. Wan, Properties of concrete prepared with low-grade recycled aggregates C \& D Waste, Constr. Build. Mater. 36 (2012) 881-889.

[34], [49] G. Menendez, V.L. Bonavetti, E.F. Irassar, Ternary blend cement concrete. Part H: transport mechanisms, Mater. Construcción. 57 (2007) 31-43.

[34], [53] H. Yiğiter, H. Yazıc1, S. Aydın, Effects of cement type, water/cement ratio and cement content on sea water resistance of concrete, Build. Environ. 42 (2007) 1770-1776. doi:10.1016/j.buildenv.2006.01.008.

[35], [54] S.A. Bernal, R. Mejía de Gutiérrez, J.L. Provis, Engineering and durability properties of concretes based on alkali-activated granulated blast furnace slag/metakaolin blends, Constr. Build. Mater. 33 (2012) 99-108. doi:10.1016/j.conbuildmat.2012.01.017.

[36], [55] J. Langford, P. Broomfiel, Monitoring the corrosion of reinforcing steel., Constr. Repair. 1 (1987) 32-6. 